Review

\title{
Kangai Injection Combined with Platinum-based Chemotherapy for the Treatment of Stage III/IV Non-Small Cell Lung Cancer: A Meta-analysis and Systematic Review of 35 Randomized Controlled Trials
}

\author{
Hongxiao Li1,2\#, Yuejin Ji3\#, Shiping Zhang1,2, Zishan $\mathrm{Gao}^{4}$, Cheng $\mathrm{Hu}^{1,2}$, Rilei Jiang ${ }^{1,2}$, Meijuan Chen ${ }^{1,2}$, \\ Guochun $\mathrm{Li}^{1,5}$, and $\mathrm{Xu}$ Zhang ${ }^{1,2}{ }^{\bowtie}$ \\ 1. School of Medicine and Life Science, Nanjing University of Chinese Medicine, Nanjing 210023, China \\ 2. Jiangsu Collaborative Innovation Center of Traditional Chinese Medicine (TCM) Prevention and Treatment of Tumor, Nanjing University of Chinese \\ Medicine, Nanjing 210023, China \\ 3. The Affiliated Hospital of Nanjing University of Chinese Medicine, Nanjing, 210029, China \\ 4. Clinical Acupuncture and Moxibustion Department, Second School of Clinical Medicine, Nanjing University of Chinese Medicine, Nanjing 210023, China \\ 5. Department of epidemiology and biostatistics, Nanjing University of Chinese Medicine, Nanjing 210023, China \\ \#Equal contributors and co-first authors.
}

$\triangle$ Corresponding authors: Dr Xu Zhang, School of Medicine and Life Science and Jiangsu Collaborative Innovation Center of Traditional Chinese Medicine (TCM) Prevention and Treatment of Tumor, Nanjing University of Chinese Medicine, Nanjing 210023, P.R. China. Email: zhangxu@njucm.edu.cn. Dr Guochun $\mathrm{Li}$, School of Medicine and Life Science and Department of epidemiology and biostatistics, Nanjing University of Chinese Medicine, Nanjing 210023, P.R. China. Email: Dr.Guochun_li@njucm.edu.cn.

(c) The author(s). This is an open access article distributed under the terms of the Creative Commons Attribution License (https://creativecommons.org/licenses/by/4.0/). See http://ivyspring.com/terms for full terms and conditions.

Received: 2018.12.01; Accepted: 2019.06.25; Published: 2019.08.28

\begin{abstract}
Objective: In an effort to inform evidence-based guidelines for clinical practice, we performed a meta-analysis to systematically evaluate the safety and efficacy of Kangai injection (KAl) plus platinum-based chemotherapy for stage III/IV non-small cell lung cancer (NSCLC).

Methods: Randomized controlled trials (RCTs) comparing KAl plus platinum-based chemotherapy (experimental group) to chemotherapy alone (control group) were electronically retrieved from the Cochrane Library, PubMed, EMbase, Web of Science, Chinese National Knowledge Infrastructure (CNKI), Chinese Biological Medicine (CBM) Database, Wanfang Database, and the VIP Database for Chinese Technical Periodicals. RCTs published from the date of inception to July 5, 2018, were included. All trials were assessed for methodological quality in accordance with the Cochrane Reviewer's Handbook for Systematic Reviews of Intervention. Meta-analysis was performed using RevMan5.3 Software and Comprehensive Meta-Analysis (CMA) 2.0.

Results: The final analysis included 35 RCTs involving 2,618 patients. Our meta-analysis revealed that KAl combined with platinum-based chemotherapy was associated with significantly greater objective response rate (ORR) $(R R=1.36,95 \% \mathrm{Cl}: 1.25-1.49, P<0.00001)$ and disease control rate (DCR) $(R R=1.14$, $95 \% \mathrm{Cl}: 1.09-1.18, P<0.00001)$, improvements in quality of life $(\mathrm{QOL})(\mathrm{RR}=1.75,95 \% \mathrm{Cl}$ : 1.59-1.93, $P<0.00001$ ), and decreases in the incidence of gastrointestinal reactions ( $R R=0.64,95 \% \mathrm{Cl}: 0.54-0.77$, $P<0.00001)$, leukocytopenia ( $R R=0.54,95 \% \mathrm{Cl}: 0.46-0.63, P<0.00001)$ and thrombocytopenia $(R R=0.52$, $95 \% \mathrm{Cl}: 0.36-0.76, P=0.0007)$ when compared with chemotherapy alone. In addition, combined treatment was associated with greater regulation of tumor immune function, as indicated by increases in the proportion of $\mathrm{NK}, \mathrm{CD}_{3}{ }^{+}$, and $\mathrm{CD}_{4}{ }^{+}$cells $(\mathrm{MD}=2.27,95 \% \mathrm{Cl}$ : 1.18-3.36, $P<0.0001$; $\mathrm{MD}=12.86,95 \% \mathrm{Cl}$ : 11.64-14.08, $P<0.00001$; and $\mathrm{MD}=5.48,95 \% \mathrm{Cl}: 2.68-8.28, \mathrm{P}=0.0001)$ and decreases in the percentage of $\mathrm{CD}_{8}{ }^{+}$cells $(\mathrm{MD}=-2.37,95 \% \mathrm{Cl}$ from -4.51 to $-0.23, P=0.03$ ).

Conclusions: From the available evidence, our results indicate that KAI plus platinum-based chemotherapy could be more effective in improving clinical efficacy, decreasing the incidence of adverse reactions and regulating the tumor immune function than chemotherapy alone in the treatment of stage
\end{abstract}


III/IV NSCLC. Nevertheless, considering the limitations of the included studies, rigorous designed, high-quality, multicenter clinical trials are still need to further confirm the results.

Key words: Kangai injection, platinum-based chemotherapy, non-small cell lung cancer, Meta-analysis, systematic review

\section{Introduction}

Globally, lung cancer remains the primary causes of cancer-related deaths [1, 2]. Non-small cell lung cancer (NSCLC) accounts for approximately $85 \%$ of cases. The 5-year survival rate for NSCLC is less than $15 \%$ [3]. Platinum-based chemotherapy as a conventional therapy is frequently utilized for the nonsurgical treatment of NSCLC due to its significant efficacy in improving tumor response rates [4-7]. However, the adverse effects of chemotherapy have been associated with poor quality of life, low survival rates, and immune dysfunction. Thus, the need for supplementary treatments that improve the clinical efficiency of treatment, enhance immune function, and minimize adverse reactions during platinum-based chemotherapy remains urgent.

Traditional Chinese medicine (TCM) has attained great popularity in the alternative and complementary treatment of advanced NSCLC [8]. Recent studies have indicated that platinum-based chemotherapy combined with TCM significantly improves efficiency and reduces toxicity relative to chemotherapy alone, which plays an irreplaceable role in clinical practice [9-11]. As a kind of Chinese patent medicine $(\mathrm{CPM})$, Kangai injection (KAI) is widely used in the treatment of NSCLC. It is an intravenous fluid made from an extraction of three Chinese herbs (i.e., ginseng, astragalus, and matrine). Its China Food and Drug Administration number is Z20026868. Active compounds of KAI include astragalus polysaccharides, astragalosides, ginsenosides, ginseng polysaccharide and oxymatfine [12], and various studies have shown that KAI possesses multiply pharmacological effects: (1)inducing tumor cell apoptosis [13, 14]; (2)inhibiting tumor cell proliferation, invasion and metastasis [15, 16]; (3)increasing the sensitivity of chemotherapy drugs and reducing adverse events caused by chemotherapy [17-19]; (4)improving the body's immune function [20-22]. In the clinic, Fan et al. found that KAI has obtained good curative effect, could ultimately prolong the survival and improve the quality of life, and mainly used in the treatment of multi-cancers, including liver, lung, colorectal cancer, etc. [23]. In terms of animal experiments, Zhou et al. found that herbal formula astragalus polysaccharide and polysaccharopeptide could show immunomodulatory effects and anti-tumor activity in mice with lung cancer [24]. Meanwhile, the results of
Xie et al. showed that Ginsenoside Rg3 could obviously inhibit the volume and weight of tumor in xenografts model, and the mechanism of Ginsenoside Rg3 anti-tumor effects may be related with inhibiting PI3K/ Akt signaling pathways [25].

Currently, a variety of trials have reported that KAI combined with chemotherapy could play a synergistic and attenuation role in NSCLC [26, 27], but, unfortunately, the conclusion is still controversial in different studies [28, 29]. Previous meta-analysis have demonstrated that the combination of KAI and platinum-based chemotherapy could increase the efficacy, improve the quality of life and reduce the adverse reactions of NSCLC [30,31], but none of the two studies evaluated the efficacy of combined therapy in regulating immune function as immunosuppression is a widely recognized complication of various chemotherapy regimens. Moreover, there have emerged some new studies evaluating the efficacy of KAI combined with platinum-based chemotherapy for NSCLC. Therefore, there is a need to update the systematic review and meta-analysis, for helping further and precisely reveal the efficacy, safety, and immune-enhancing effects of KAI, which will be beneficial to the treatment of advanced non-small cell lung cancer and the popularization of KAI.

\section{Materials and Methods}

The present meta-analysis and systematic review were conducted in accordance with the Preferred Reported Items for Systematic Review and Meta-analysis (PRISMA) guidelines. Our systematic review is registered in the International Prospective Register of Systematic Reviews (PROSPERO) database (registration number: CRD42018103626).

\section{Literature source and search strategy}

We searched the following electronic databases up to July 5, 2018: the Cochrane Library, PubMed, EMbase, Web of Science, Chinese National Knowledge Infrastructure (CNKI), Chinese Biological Medicine Database (CBM), Wangfang Database, and the VIP Database for Chinese Technical Periodicals (VIP). Two independent investigators searched for eligible according to the following search strategy: ("Lung Cancer" [Mesh] OR "Non-small Cell Lung Cancer" [Mesh] OR "Non-small Cell Lung Cancer" OR 
"NSCLC") AND ("Chemotherapy" OR "chemotherapy" OR "chemotherapeutics" OR "chemical therapy") AND ("Kangai injection"). A detailed search strategy of PubMed was shown in supplementary materials. Clinical studies published in languages other than English or Chinese were excluded.

\section{Inclusion criteria}

Our analysis included randomized controlled trials (RCTs) comparing a platinum-based chemotherapy group (control) with a chemotherapy plus KAI group (experimental), regardless of blinding or allocation concealment. Eligible studies included patients diagnosed with Stage III-IV NSCLC via pathological or cytological examination, with Karnofsky performance scores (KPS) $\geq 60$ or survival times $\geq 3$ months. Eligible patients were required to exhibit no obvious abnormalities in the liver, kidney, cardiac function, or contraindications for chemotherapy. Additional inclusion criteria were as follows: no age, gender, race, nationality, or regional restrictions in either arm; no significant differences in baseline conditions between the experimental and control groups $(\mathrm{P}>0.05)$; inclusion of at least one outcome indicator (objective response rate, quality of life, adverse effects, immune function).

\section{Exclusion criteria}

Studies involving patients with other primary tumors; those with severe cardiovascular, hepatic, or renal diseases; and those in which treatment was combined with surgery, radiotherapy, or other TCM therapies were excluded. Non-RCTs (animal experiments, case reports, cohort studies, review articles, etc.), duplicate studies, and studies reporting no outcome measures were also excluded. Studies in which KAI was administered non-intravenously (e.g., oral granules) and those of insufficient quality (i.e., incomplete information, obvious error, inappropriate statistical methods, non-rigorous experimental design, etc.) were excluded as well.

\section{Outcome indicators and evaluation criteria}

The objective tumor response rate (ORR) and disease control rate (DCR) were evaluated in accordance with World Health Organization (WHO) evaluation criteria or the Response Evaluation Criteria in Solid Tumors (RECIST). Responses were categorized as complete relief (CR), partial remission $(\mathrm{PR})$, stable disease (SD), or progressive disease (PD). ORR was calculated as follows: (CR + PR) / total number of cases $\times 100 \%$, and DCR was calculated as follows: $(\mathrm{CR}+\mathrm{PR}+\mathrm{SD}) /$ total number of cases $\times$ $100 \%$.
The KPS was used to assess the patient's quality of life (QOL). Patients exhibiting KPS increases or decreases of more than 10 points were considered to have experienced improvement or deterioration, respectively. QOL was considered stable in patients exhibiting changes within this range. Rates of improvement were calculated as follows: number of patients exhibiting improvement / total number of cases $\times 100 \%$.

We adopted the WHO Recommendations for Grading of Acute and Subacute Toxicity to evaluate the adverse reactions of chemotherapy, which were classified into five levels: 0, I, II, III, and IV. In this meta-analysis, we examined only gastrointestinal reactions (nausea and vomiting) and myelosuppression (leukocyte, hemoglobin and platelet) of grade II or higher.

The incidence of alterations in cellular immune function (i.e., natural killer cells (NK), $\mathrm{CD}_{3}{ }^{+}, \mathrm{CD}_{4}{ }^{+}$, $\mathrm{CD}_{8}{ }^{+}$, and $\mathrm{CD}_{4}{ }^{+} / \mathrm{CD}_{8}{ }^{+}$ratio) was also used to estimate the efficacy of KAI. analysis of immune alterations in included studies were performed using immunocytochemistry or flow cytometry.

\section{Data extraction and quality assessment}

Two investigators (Hongxiao $\mathrm{Li}$ and Yuejin Ji) independently extracted and cross-checked the general characteristics of eligible studies. Discrepancies were resolved via discussion with a third reviewer (Shiping Zhang). The following features were extracted from each article: name of the first author, publication year, number of patients in each group, sex, age, physical status, tumor stage, intervention details (course of treatment, chemotherapy regimens, etc.), outcome indicators. For trials reporting incomplete or ambiguous data, we contacted the corresponding author via email for clarification. If no response was obtained after three attempts, the article in question was removed from the analysis. Two reviewers (Hongxiao Li and Yuejin Ji) evaluated the methodological quality of each included RCT based on the following items, in accordance with the Cochrane Collaboration's Risk of Bias criteria [32]: random sequence generation (selection bias), allocation concealment (selection bias), blinding of participants and personnel (performance bias), blinding of outcome data (detection bias), incomplete outcome data (attrition bias), selective reporting (reporting bias), and other biases.

\section{Statistical analysis}

As required by the Cochrane Collaboration, we utilized Review Manager 5.3 software and Comprehensive Meta-Analysis (CMA) 2.0 for the 
present meta-analysis. Risk ratios (RRs) and mean differences (MDs) were used to express therapeutic efficacy for dichotomous outcomes and continuous data, respectively. Both RRs and MDs were calculated using the effect value and $95 \%$ confidence intervals (CI). P values $<0.05$ were considered to indicate statistical significance. Inconsistency $\left(I^{2}\right)$ was used to detect the heterogeneity between studies, and a fixed-effects model was applied to calculate the pooled statistics when there was no significant heterogeneity $\left(I^{2}<50 \%\right)$. In other cases, a random-effects model was adopted $\left(I^{2}>50 \%\right)$. The stability of pooled results was confirmed by sensitivity analysis, which were performed using three methods: altering the combined-effects model, removing the study with the greatest weight, and exclusion of studies one-by-one. Moreover, funnel plots and Egger's tests were used to estimate the potential publication bias. Trial sequential analysis (TSA) was performed to evaluate the robustness of the results and meta-analytic sample size, while meta-regression analysis (MRA) was performed to explore the effects of potential heterogeneity and confounders on outcomes.

\section{Results}

\section{Search results}

Our initial search identified a total of 562 relevant articles. Following the exclusion of 197 duplicate articles and a review of the remaining titles and abstracts, we evaluated the full text of 103 articles according to inclusion and exclusion criteria. An additional 68 articles were excluded mainly because they were reviews, non-RCTs, did not report relative outcomes, utilized inappropriate interventions or data extraction methods, and included data errors. In total, 35 RCTs were included in this meta-analysis. The screening process and results are shown in were shown in Figure 1.

\section{Basic characteristics of the included studies}

A total of 2,618 patients were enrolled in the 35 included studies [26, 27, 33-65], all of which were conducted and published in China. Across these 35 studies, there were 1,328 and 1,290 patients in the experimental and control groups, respectively. Participant ages ranged from 21 to 85 years. Navelbine ${ }^{\circledR}$ (vinorelbine) plus platinum (NP) was the most frequently utilized chemotherapy regimen,

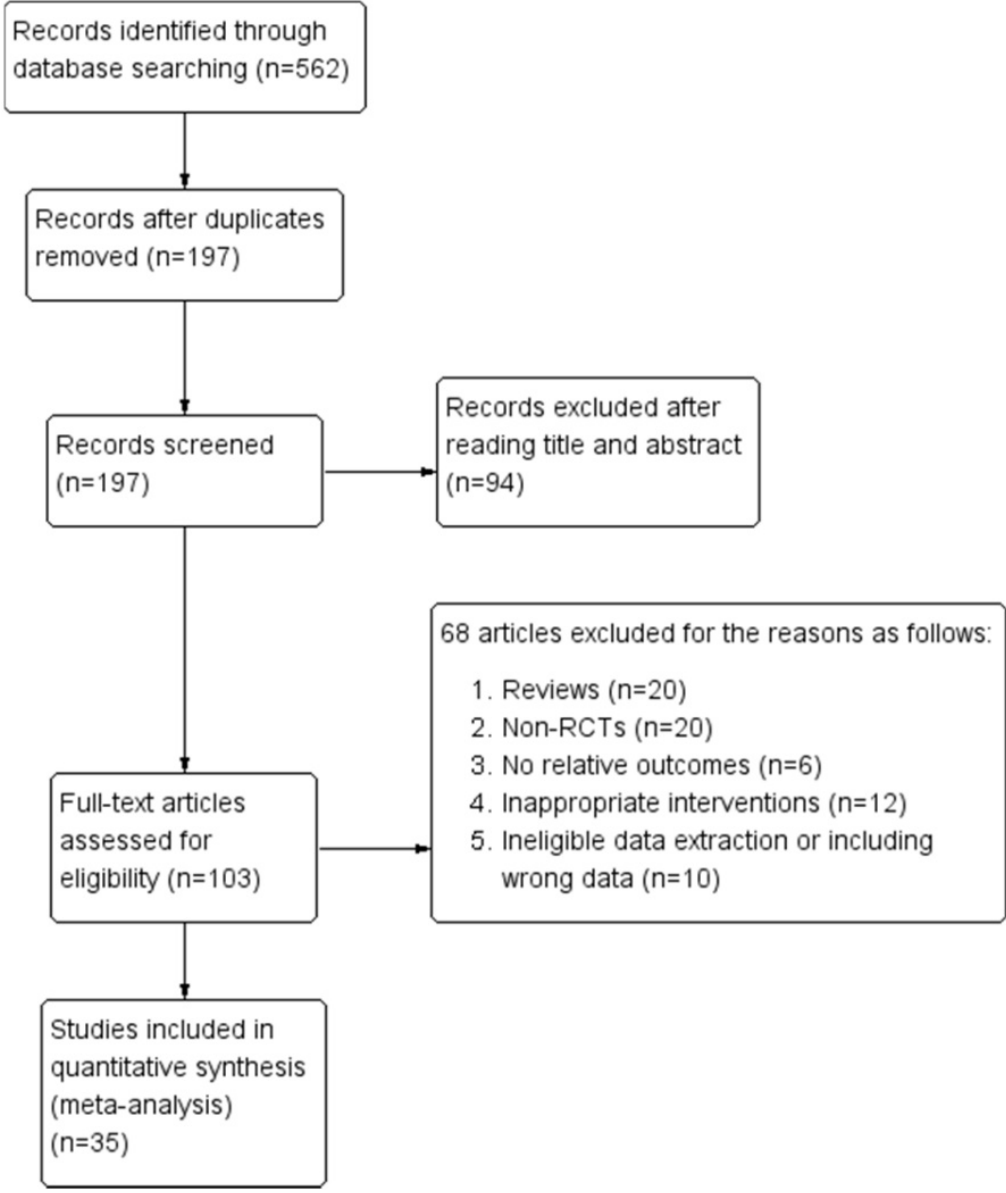

Figure 1: Flow diagram of screening process for eligible articles. 
followed by Taxol® (paclitaxel) plus platinum (TP), docetaxel plus platinum (DP), gemcitabine plus platinum (GP), 5-fluorouracil plus platinum (FP), pemetrexed plus platinum (PP), and vindesine plus platinum (VP). A total of 33 articles [27, 33-41, 43-65] reported ORR, 32 articles [27, 33-41, 43-53, 55-65] reported DCR. In addition, 27 studies [27, 36-38, 40-56, 59-62, 64, 65] assessed QOL using the KPS. Twelve studies [36, 37, 39, 41, 43, 44, 48, 52, 53, 55, 57, 62] provided outcomes regarding gastrointestinal reactions, while 15 provided outcomes regarding leukocytopenia [27, 36, 37, 39-41, 43, 44, 48, 52, 53, 55, 57, 62, 64], 4 documents reported hemoglobin deficiency [36, 37, 43, 64], and 6 studies assessed thrombocytopenia [36, 37, 43, 57, 62, 64]. Immune function outcomes were assessed in nine trials [33-35, $42,50-52,61,64]$. The basic characteristics of the included studies are shown in Table 1.

\section{Evaluation of methodological quality}

The detailed results of the methodological evaluation are shown in Figures 2, 3 and Table S1. While all articles mentioned randomization, only nine trials indicated the specific method of random allocation [27, 34, 42, 47, 51, 53, 57, 63, 64]. Only one study reported allocation concealment, which was implemented using an opaque envelope [42]. None of the included studies described double-blinding or blinding of outcome assessments. Six studies reported rates of follow-up and withdrawal (attrition bias) [39, $44,50,57,58,64]$. With regard to reporting bias, because we observed that the results reported by four studies were less than the evaluation index $[26,38,45$, 63], these four studies were classified as "high risk". Due to insufficient data among the retrieved studies, results for other forms of bias were unclear.

Table 1: Basic characteristics of the included studies.

\begin{tabular}{|c|c|c|c|c|c|c|c|c|c|}
\hline \multirow[t]{2}{*}{ Study ID } & \multirow[t]{2}{*}{ Cases $(\mathrm{T} / \mathrm{C})$} & \multirow[t]{2}{*}{ Age (y) } & \multirow{2}{*}{$\begin{array}{c}\text { Gender } \\
(\mathrm{M} / \mathrm{F})\end{array}$} & \multirow{2}{*}{$\begin{array}{l}\text { Physical } \\
\text { status } \\
\text { (KPS) }\end{array}$} & \multirow[t]{2}{*}{ Stage } & \multicolumn{2}{|l|}{ Experimental group } & \multirow{2}{*}{$\begin{array}{l}\text { Control group } \\
\text { (chemotherapy } \\
\text { regimen) }\end{array}$} & \multirow[t]{2}{*}{ Indicators } \\
\hline & & & & & & Intervention & $\begin{array}{l}\text { Number of KAI } \\
\text { cycles }\end{array}$ & & \\
\hline $\begin{array}{l}\text { Huang YN, } \\
2011\end{array}$ & $286(144 / 142)$ & $42-71$ & $194 / 92$ & KPS $\geq 60$ & IIIa-IV & $\mathrm{NP}+\mathrm{KAI}(60 \mathrm{ml} / \mathrm{d}, \mathrm{d} 1-\mathrm{d} 14)$ & 2 & $\mathrm{NP}$ & $1,2,3,4,5,7$ \\
\hline He JF, 2011 & $61(31 / 30)$ & $51-76$ & $47 / 14$ & KPS $>60$ & IIIa-IV & $\mathrm{TP}+\mathrm{KAI}(40 \mathrm{ml} / \mathrm{d}, \mathrm{d} 1-\mathrm{d} 14)$ & 2 & $\mathrm{TP}$ & 1,2 \\
\hline Wei HY, 2013 & $64(32 / 32)$ & $37-65$ & $42 / 22$ & $\mathrm{KPS} \geq 70$ & IIIb-IV & $\mathrm{DP}+\mathrm{KAI}(40 \mathrm{ml} / \mathrm{d}, \mathrm{d} 1-\mathrm{d} 21)$ & 2 & DP & $1,2,3,5,6,7,8$ \\
\hline Sun LJ, 2008 & $108(60 / 48)$ & $45-74$ & $86 / 22$ & KPS>70 & III-IV & $\mathrm{TP}+\mathrm{KAI}(50 \mathrm{ml} / \mathrm{d}, \mathrm{d} 1-\mathrm{d} 30)$ & 1 & $\mathrm{TP}$ & $1,2,3$ \\
\hline Zou Y, 2013 & $76(38 / 38)$ & $52-74$ & $52 / 24$ & $\mathrm{KPS} \geq 60$ & III-IV & $\mathrm{NP}+\mathrm{KAI}(40 \mathrm{ml} / \mathrm{d}, \mathrm{d} 1-\mathrm{d} 21)$ & 2 & NP & $1,2,4,5$ \\
\hline Luo JH, 2009 & $64(32 / 32)$ & $30-75$ & $51 / 13$ & KPS $>60$ & IIIb-IV & $\mathrm{NP}+\mathrm{KAI}(40 \mathrm{ml} / \mathrm{d}, \mathrm{d} 1-\mathrm{d} 21)$ & 2 & NP & $1,2,3,4,5,8$ \\
\hline Ma XP, 2012 & $52(26 / 26)$ & $31-76$ & $33 / 19$ & KPS $>60$ & IIIb-IV & $\mathrm{DP}+\mathrm{KAI}(30 \mathrm{ml} / \mathrm{d}, \mathrm{d} 1-\mathrm{d} 30)$ & 1 & DP & $1,2,3,4,5$ \\
\hline Zhang XL, 2005 & $62(30 / 32)$ & $35-76$ & $43 / 19$ & KPS $>60$ & III-IV & $\mathrm{NP}+\mathrm{KAI}(40 \sim 60 \mathrm{ml} / \mathrm{d}, \mathrm{d} 1-\mathrm{d} 20)$ & 1 & NP & $1,2,3,8$ \\
\hline $\begin{array}{l}\text { Huang RW, } \\
2006\end{array}$ & $50(25 / 25)$ & $35-78$ & $34 / 16$ & KPS $\geq 60$ & IIIb-IV & $\mathrm{NP}+\mathrm{KAI}(20 \sim 30 \mathrm{ml} / \mathrm{d}, \mathrm{d} 1-\mathrm{d} 21)$ & 2 & $\mathrm{NP}$ & $1,2,3$ \\
\hline Jing H, 2007 & $97(51 / 46)$ & $35-73$ & $61 / 36$ & $\mathrm{KPS} \geq 60$ & IIIa-IV & $\mathrm{NP} / \mathrm{VP}+\mathrm{KAI}(40 \mathrm{ml} / \mathrm{d}, \mathrm{d} 1-\mathrm{d} 14)$ & 3 & $\mathrm{NP} / \mathrm{VP}$ & $1,2,4,5,7$ \\
\hline Zou H, 2008 & $51(26 / 25)$ & $31-77$ & $39 / 12$ & $\mathrm{KPS} \geq 60$ & IIIb-IV & $\mathrm{DP}+\mathrm{KAI}(40 \sim 50 \mathrm{ml} / \mathrm{d}, \mathrm{d} 1-\mathrm{d} 14)$ & 2 & DP & $1,2,3$ \\
\hline Wu DH, 2009 & $56(28 / 28)$ & NR & $43 / 13$ & KPS $>60$ & IIIb-IV & $\mathrm{TP}+\mathrm{KAI}(50 \mathrm{ml} / \mathrm{d}, \mathrm{d} 1-\mathrm{d} 14)$ & 2 & $\mathrm{TP}$ & $1,2,3,4,5$ \\
\hline Wang LF, 2010 & $64(32 / 32)$ & $30-76$ & $46 / 18$ & $\mathrm{KPS} \geq 70$ & III-IV & $\mathrm{TP}+\mathrm{KAI}(50 \mathrm{ml} / \mathrm{d}, \mathrm{d} 1-\mathrm{d} 7)$ & 4 & $\mathrm{TP}$ & $1,2,3$ \\
\hline Ge CZ, 2011 & $64(32 / 32)$ & $70-79$ & $47 / 17$ & $\mathrm{KPS} \geq 60$ & IIIa-IV & $\mathrm{GP}+\mathrm{KAI}(30 \mathrm{ml} / \mathrm{d}, \mathrm{d} 1-\mathrm{d} 21)$ & 2 & GP & $1,2,3$ \\
\hline Jiang L, 2011 & $65(35 / 30)$ & $50-79$ & $44 / 21$ & $\mathrm{KPS} \geq 60$ & IIIlb-IV & $\mathrm{DP}+\mathrm{KAI}(40 \mathrm{ml} / \mathrm{d}, \mathrm{d} 1-\mathrm{d} 12)$ & 1 & DP & $1,2,3$ \\
\hline Zheng ZP, 2012 & $48(25 / 23)$ & NR & $34 / 14$ & KPS $>60$ & IIIb-IV & $\begin{array}{l}\mathrm{NP} / \mathrm{TP} / \mathrm{GP} / \mathrm{PP}+\mathrm{KAI}(50 \mathrm{ml} / \mathrm{d} \\
\mathrm{d} 1-\mathrm{d} 15)\end{array}$ & 4 & $\mathrm{NP} / \mathrm{TP} / \mathrm{GP} / \mathrm{PP}$ & 3,8 \\
\hline Tu JG, 2012 & $63(32 / 31)$ & $70-85$ & $41 / 22$ & KPS $>60$ & IIIa-IV & $\mathrm{DP}+\mathrm{KAI}(30 \mathrm{ml} / \mathrm{d}, \mathrm{d} 1-\mathrm{d} 14)$ & 2 & DP & $1,2,3,4,5,6,7$ \\
\hline Chen L, 2014 & $83(41 / 42)$ & NR & $53 / 30$ & KPS $>60$ & IIIa-IV & $\mathrm{NP}+\mathrm{KAI}(40 \mathrm{ml} / \mathrm{d}, \mathrm{d} 1-\mathrm{d} 21)$ & 2 & NP & $1,2,8$ \\
\hline Zhou ZY, 2014 & $80(40 / 40)$ & $62-76$ & $44 / 36$ & $\mathrm{KPS} \geq 60$ & IIIb-IV & $\mathrm{GP}+\mathrm{KAI}(40 \mathrm{ml} / \mathrm{d}, \mathrm{d} 1-\mathrm{d} 14)$ & 4 & GP & $1,2,8$ \\
\hline Liu S, 2014 & $72(36 / 36)$ & $27-70$ & $50 / 22$ & $\mathrm{KPS} \geq 70$ & IIIb-IV & $\begin{array}{l}\mathrm{TP} / \mathrm{DP} / \mathrm{GP} / \mathrm{NP}+\mathrm{KAI}(60 \mathrm{ml} / \mathrm{d}, \\
\mathrm{d} 1-\mathrm{d} 14)\end{array}$ & 2 & $\mathrm{TP} / \mathrm{DP} / \mathrm{GP} / \mathrm{NP}$ & $1,2,3,4,5,6,7$ \\
\hline Huang JT, 2014 & $56(28 / 28)$ & $67-75$ & $33 / 23$ & KPS $>60$ & III-IV & $\mathrm{TP}+\mathrm{KAI}(50 \mathrm{ml} / \mathrm{d}, \mathrm{d} 1-\mathrm{d} 14)$ & 2 & $\mathrm{TP}$ & $1,2,3,4,5,6,7$ \\
\hline Wang ZF, 2017 & $76(38 / 38)$ & $21-74$ & $54 / 22$ & $\mathrm{KPS} \geq 60$ & IV & $\mathrm{FP}+\mathrm{KAI}(40 \mathrm{ml} / \mathrm{d}, \mathrm{d} 1-\mathrm{d} 21)$ & 1 & $\mathrm{FP}$ & 8 \\
\hline Luo JH, 2017 & $54(27 / 27)$ & $37-72$ & $28 / 26$ & $\mathrm{KPS} \geq 60$ & IIIb-IV & $\mathrm{NP}+\mathrm{KAI}(40 \mathrm{ml} / \mathrm{d}, \mathrm{d} 1-\mathrm{d} 21)$ & 2 & NP & 1,2 \\
\hline Yang XY, 2010 & $60(30 / 30)$ & $65-70$ & $37 / 23$ & KPS $>60$ & IIIb-IV & $\mathrm{GP}+\mathrm{KAI}(40 \mathrm{ml} / \mathrm{d}, \mathrm{d} 1-\mathrm{d} 14)$ & 4 & GP & $1,2,3,8$ \\
\hline Li JS, 2011 & $60(30 / 30)$ & $50-79$ & $43 / 17$ & $\mathrm{KPS} \geq 60$ & IIIa-IV & $\mathrm{TP}+\mathrm{KAI}(40 \mathrm{ml} / \mathrm{d}, \mathrm{d} 1-\mathrm{d} 14)$ & 3 & $\mathrm{TP}$ & $1,2,3,8$ \\
\hline Wei HD, 2012 & $100(50 / 50)$ & $44-72$ & $58 / 42$ & $\mathrm{KPS} \geq 60$ & IIIb-IV & $\mathrm{NP}+\mathrm{KAI}(40 \mathrm{ml} / \mathrm{d}, \mathrm{d} 1-\mathrm{d} 21)$ & 4 & $\mathrm{NP}$ & $1,2,3,4,5$ \\
\hline Li ZJ, 2013 & $68(35 / 33)$ & $43-75$ & $45 / 23$ & $\mathrm{KPS} \geq 60$ & IIIa-IV & $\mathrm{NP}+\mathrm{KAI}(40 \mathrm{ml} / \mathrm{d}, \mathrm{d} 1-\mathrm{d} 10)$ & 3 & $\mathrm{NP}$ & $1,2,3,5$ \\
\hline Shi L, 2011 & $58(29 / 29)$ & $34-70$ & $36 / 22$ & KPS>70 & IIIb-IV & $\mathrm{TP}+\mathrm{KAI}(30 \mathrm{ml} / \mathrm{d}, \mathrm{d} 1-\mathrm{d} 14)$ & 2 & $\mathrm{TP}$ & $1,2,3,4,5$ \\
\hline Zhang MJ, 2009 & $120(60 / 60)$ & $29-75$ & $76 / 44$ & KPS $>60$ & IIIa-IV & $\mathrm{TP}+\mathrm{KAI}(40 \mathrm{ml} / \mathrm{d}, \mathrm{d} 1-\mathrm{d} 21)$ & 2 & $\mathrm{TP}$ & 1,3 \\
\hline Wen JY, 2006 & $78(40 / 38)$ & $24-76$ & $67 / 11$ & KPS $>60$ & IIIb-IV & $\mathrm{NP}+\mathrm{KAI}(50 \mathrm{ml} / \mathrm{d}, \mathrm{d} 1-\mathrm{d} 14)$ & 4 & NP & $1,2,3$ \\
\hline Zhang JL, 2010 & $60(30 / 30)$ & $51-78$ & $45 / 15$ & KPS $>60$ & IIIa-IV & $\mathrm{TP}+\mathrm{KAI}(40 \mathrm{ml} / \mathrm{d}, \mathrm{d} 1-\mathrm{d} 14)$ & 2 & $\mathrm{TP}$ & $1,2,3$ \\
\hline Zhao JP, 2009 & $75(38 / 37)$ & $46-70$ & $47 / 28$ & KPS $\geq 60$ & IIIb-IV & $\mathrm{DP}+\mathrm{KAI}(60 \mathrm{ml} / \mathrm{d}, \mathrm{d} 1-\mathrm{d} 15)$ & 2 & DP & $1,2,3,4,5$ \\
\hline Hu DX, 2007 & $43(21 / 22)$ & NR & $29 / 14$ & KPS $>60$ & IIIa-IV & $\mathrm{NP}+\mathrm{KAI}(40 \sim 60 \mathrm{ml} / \mathrm{d}, \mathrm{d} 1-\mathrm{d} 21)$ & 2 & NP & 1,2 \\
\hline $\begin{array}{l}\text { Guang XH, } \\
2015\end{array}$ & $89(46 / 43)$ & $40-70$ & $50 / 39$ & $\mathrm{KPS} \geq 60$ & IIIb-IV & $\mathrm{GP}+\mathrm{KAI}(40 \mathrm{ml} / \mathrm{d}, \mathrm{d} 1-\mathrm{d} 14)$ & 2 & GP & $1,2,3,5$ \\
\hline Zhang SQ, 2014 & $55(30 / 25)$ & $45-84$ & $43 / 12$ & $\mathrm{KPS} \geq 60$ & III-IV & $\mathrm{TP}+\mathrm{KAI}(60 \mathrm{ml} / \mathrm{d}, \mathrm{d} 1-\mathrm{d} 21)$ & 2 & $\mathrm{TP}$ & $1,2,3$ \\
\hline
\end{tabular}




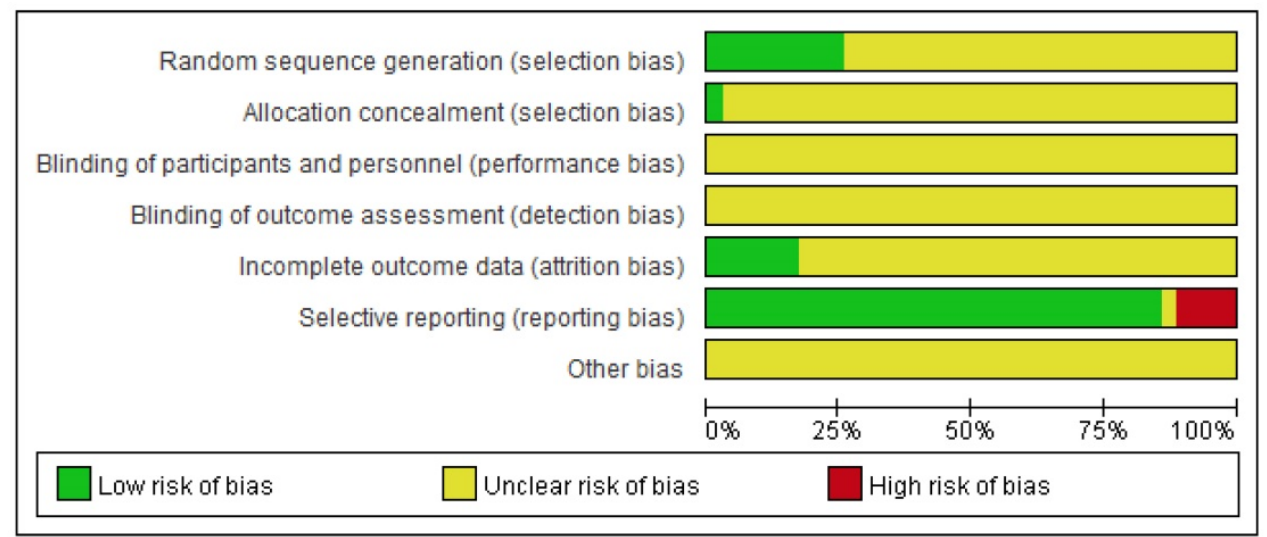

Figure 2: Summary of the risk of bias for each included study. “+” (green): low risk of bias; “"” (yellow): unclear risk of bias; “.” (red): high risk of bias.

\section{ORR}

A total of 33 studies reported the ORR, yielding a total sample of 2,494 patients $(1,265$ in the experimental group and 1,229 in the control group). Subgroup analyses were performed based on whether WHO or RECIST criteria were utilized. Heterogeneity analysis revealed that all included studies exhibited good homogeneity with regard to the consistency of their results $\left(P=0.78, I^{2}=0 \%\right)$ (Figure 4). Therefore, the fixed-effects model was applied. Our results indicated that ORR were significantly greater among patients in the KAI group than among those receiving chemotherapy alone (WHO criteria: $\mathrm{RR}=1.37,95 \% \mathrm{CI}$ : 1.25-1.52, $P<0.00001$; RECIST criteria: $R R=1.31,95 \%$ CI: 1.07-1.60, $P<0.010$; overall effect: $R R=1.36,95 \% \mathrm{CI}$ : $1.25-1.49, P<0.00001)$.

\section{DCR}

A total of 32 studies reported the DCR, yielding a total sample of 2,374 patients $(1,205$ in the experimental group and 1,169 in the control group). We performed subgroup analysis due to the different criteria. Heterogeneity analysis revealed that there is a good homogeneity with regard to the consistency of the results $\left(P=0.92, I^{2}=0 \%\right)$ (Figure 5). Therefore, the fixed-effects model was applied. Our results showed a significant improvement of DCR among patients in the KAI group (WHO criteria: $\mathrm{RR}=1.13,95 \% \mathrm{CI}$ : 1.09-1.18, $P<0.00001$; RECIST criteria: $R R=1.15,95 \%$ CI: $1.04-1.26, P=0.004$; overall effect: $R R=1.14,95 \% C I$ : $1.09-1.18, P<0.00001)$.

\section{QOL}

A total of 27 studies assessed QOL, yielding a total sample of 2,048 patients $(1,041$ in the experimental group and 1,007 in the control group). As shown in Figure 6, we utilized a fixed-effects model to assess the homogeneity of the included studies $\left(P=0.88, I^{2}=0 \%\right)$. Overall RRs suggested that the combination of KAI and chemotherapy was more effective at improving QOL than chemotherapy alone (RR=1.75, 95\% CI: 1.59-1.93, $P<0.00001)$.

\section{Gastrointestinal reactions}

Twelve studies reported the rate of gastrointestinal reactions, yielding a total sample of 1,055 patients (532 in the experimental group and 523 in the control group). As there was no significant heterogeneity in the results $\left(P=0.10, I^{2}=37 \%\right)$ (Figure $7)$, we performed quantitative data synthesis using a fixed-effects model. Overall RRs suggested that the combination of KAI and chemotherapy ( $R R=0.64,95 \%$ CI: $0.54-0.77, \quad P<0.00001)$ was more effective in reducing the incidence of gastrointestinal reactions than chemotherapy alone.

\section{Myelosuppression}

To evaluate the role of KAI in improving myelosuppression rigorously, we performed meta-analysis of leukocyte, hemoglobin and platelet, respectively. Of all the studies included, 15 documents reported the incidence of leukocytopenia, 4 studies reported hemoglobin deficiency, and 6 studies assessed thrombocytopenia. We conducted a fixed-effects model for quantitative data synthesis according to the homogeneity of the results: leukocytopenia $\quad\left(P=0.82, \quad I^{2}=0 \%\right), \quad$ hemoglobin deficiency $\left(P=0.80, I^{2}=0 \%\right)$, and thrombocytopenia $\left(P=0.98, I^{2}=0 \%\right)$ (Figure 8a-c). It is meaning for us to find that KAI combined with platinum-based chemotherapy could only reduce the incidence of leukocytopenia ( $R R=0.54,95 \%$ CI: 0.46-0.63, $P<0.00001)$ and thrombocytopenia $(\mathrm{RR}=0.65,95 \% \mathrm{CI}$ : $0.34-1.24, P=0.19)$ in this meta-analysis, while there is no significant difference in hemoglobin deficiency between the two groups ( $R R=0.52,95 \% \mathrm{CI}: 0.36-0.76$, $P=0.0007$ ). 


\section{Immune function}

Four separate articles reported $\mathrm{NK}$ and $\mathrm{CD}_{3}{ }^{+}$ data, yielding 276 patients in the NK group and 269 patients in the $\mathrm{CD}_{3}{ }^{+}$group. A fixed-effects model was used for quantitative data synthesis due to the homogeneity of the results: NK $\left(P=0.91, I^{2}=0 \%\right), \mathrm{CD}_{3}{ }^{+}$ $\left(P=0.14, I^{2}=45 \%\right)$ (Figure 9a-b). Analysis of the pooled MD revealed that KAI combined with chemotherapy significantly improved NK $(\mathrm{MD}=2.27,95 \% \mathrm{CI}$ : 1.18-3.36, $P<0.0001)$ and $\mathrm{CD}_{3}{ }^{+}$values $(\mathrm{MD}=12.86,95 \%$ CI: 11.64-14.08, $P<0.00001)$ when compared with chemotherapy alone.

Due to the heterogeneity of $\mathrm{CD}_{4}{ }^{+}(\mathrm{P}<0.00001$, $\left.I^{2}=86 \%\right), \mathrm{CD}_{8}{ }^{+}\left(\mathrm{P}=0.0003, I^{2}=81 \%\right)$, and $\mathrm{CD}_{4}{ }^{+} / \mathrm{CD}_{8}{ }^{+}$ $\left(\mathrm{P}<0.00001, I^{2}=90 \%\right)$ data (Figure 9c-e), we utilized a random-effects model for data synthesis. Our results indicated that the combination of KAI and chemotherapy significantly increased the percentage of $\mathrm{CD}_{4}{ }^{+}$cells (MD $=5.48,95 \% \mathrm{CI}: 2.68-8.28, P=0.0001$ ) and significantly decreased the percentage of $\mathrm{CD}_{8}{ }^{+}$ cells $(\mathrm{MD}=-2.37,95 \% \mathrm{CI}$ from -4.51 to $-0.23, P=0.03)$. However, there was no significance difference in $\mathrm{CD}_{4}{ }^{+} / \mathrm{CD}_{8}{ }^{+}$ratio between the two groups $(\mathrm{MD}=0.12$, $95 \%$ CI from -0.07 to $0.30, P=0.21$ ).

\section{Publication bias}

Funnel plots and Egger's tests were used to examine the potential publication bias among studies reporting ORR. As shown in Figure 10, although one point lies outside of the funnel, the plot is nearly symmetric, suggestive of a lack of publication bias. In addition, Egger's tests revealed that there was no significant bias with regard to ORR $(P=0.285)$, consistent with the results of funnel plot analysis.

Table 2: Sensitivity analysis of this study.

\begin{tabular}{llllllll}
\hline $\begin{array}{l}\text { Immune } \\
\text { index }\end{array}$ & $N$ & MD (95\%CI) & $I^{2}$ & $\begin{array}{l}\text { Excluded } \\
\text { articles }\end{array}$ & $N$ & MD $(95 \% \mathrm{CI})$ & $I^{2}$ \\
\hline $\mathrm{CD}_{4}{ }^{+}$ & 5 & $5.48[2.68,8.28]$ & $86 \%$ & {$[45,48]$} & 3 & $8.01[6.28,9.73]$ & $0 \%$ \\
$\mathrm{CD}_{8}{ }^{+}$ & 5 & $-2.37[-4.51,-0.23]$ & $81 \%$ & {$[36,45,48]$} & 2 & $-6.27[-8.86,-3.69]$ & $0 \%$ \\
$\mathrm{CD}_{4}{ }^{+} / \mathrm{CD}_{8}{ }^{+}$ & 9 & $0.12[-0.07,0.30]$ & $90 \%$ & {$[19,45,48]$} & 6 & $0.26[0.13,0.38]$ & $41 \%$ \\
\hline
\end{tabular}

$\mathrm{N}$, the number of studies. "reference number.

\section{Sensitivity analysis}

Based on the results of our meta-analysis, we performed a sensitivity analysis for outcomes with high heterogeneity: $\mathrm{CD}_{4}{ }^{+}, \mathrm{CD}_{8}{ }^{+}$, and $\mathrm{CD}_{4}{ }^{+} / \mathrm{CD}_{8}{ }^{+}$. This analysis indicated that the results of the fixed-effects and random-effects models were consistent, suggesting that the results of our meta-analysis were stable and reliable. We then removed studies with the greatest weight and those exhibiting significant differences (Table 2), which reversed the resultant heterogeneity, suggesting that the excluded articles may have been the source of heterogeneity.
Re-evaluation of the excluded studies revealed that differences in the dosage and course of chemotherapy may have been responsible for these results.

\begin{tabular}{|c|c|c|c|c|c|c|c|}
\hline & 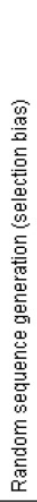 & 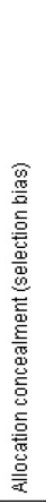 & 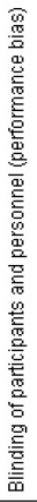 & 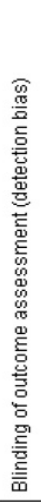 & 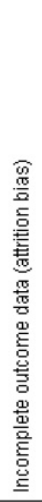 & 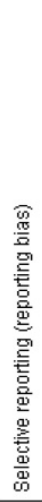 & 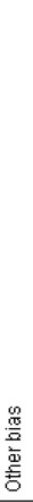 \\
\hline Chen L,2014 & + & $?$ & $?$ & $?$ & $?$ & + & $?$ \\
\hline$G e C Z, 2011$ & $?$ & $?$ & $?$ & $?$ & $?$ & O & $?$ \\
\hline Guang $\times H, 2015$ & + & $?$ & $?$ & $?$ & $?$ & $\oplus$ & $?$ \\
\hline $\mathrm{He} J \mathrm{JF}, 2011$ & + & $?$ & $?$ & $?$ & $?$ & $\theta$ & $?$ \\
\hline Huang JT,2014 & $?$ & $?$ & ? & $?$ & $?$ & $\oplus$ & ? \\
\hline Huang RW,2006 & $?$ & $?$ & ? & $?$ & $?$ & + & $?$ \\
\hline Huang $Y N, 2011$ & $?$ & $?$ & $?$ & ? & ? & + & ? \\
\hline $\mathrm{Hu} D \times, 2007$ & ? & $?$ & ? & $?$ & + & + & $?$ \\
\hline Jiang L,2011 & ? & $?$ & ? & ? & $?$ & + & ? \\
\hline Jing $H_{1}, 2007$ & + & $?$ & $?$ & ? & + & + & ? \\
\hline Li JS, 2011 & + & $?$ & $?$ & $?$ & $?$ & + & ? \\
\hline Liu S,2014 & ? & $?$ & $?$ & $?$ & $?$ & + & ? \\
\hline Li ZJ,2013 & $?$ & $?$ & ? & $?$ & $?$ & $\oplus$ & $?$ \\
\hline Luo JH,2009 & $?$ & $?$ & ? & $?$ & $?$ & $?$ & $?$ \\
\hline Luo JH,2017 & $?$ & $?$ & ? & $?$ & $?$ & $O$ & $?$ \\
\hline $\operatorname{MaXP}, 2012$ & $?$ & $?$ & ? & $?$ & $?$ & + & $?$ \\
\hline Shi L,2011 & ? & $?$ & ? & $?$ & $?$ & + & $?$ \\
\hline Sun LJ,2008 & ? & $?$ & $?$ & $?$ & $?$ & + & ? \\
\hline Tu JG 2012 & ? & $?$ & $?$ & $?$ & $?$ & + & ? \\
\hline Wang LF, 2010 & ? & ? & $?$ & $?$ & $?$ & + & ? \\
\hline lang ZF, 2017 & $?$ & $?$ & $?$ & ? & $?$ & + & ? \\
\hline Wei HD,2012 & $?$ & $?$ & $?$ & $?$ & $\oplus$ & + & $?$ \\
\hline Wei HY,2013 & + & $?$ & ? & $?$ & + & $\oplus$ & $?$ \\
\hline Wen JY,2006 & $?$ & $?$ & $?$ & $?$ & $?$ & $\oplus$ & $?$ \\
\hline Wu DH,2009 & + & $?$ & ? & $?$ & $?$ & + & ? \\
\hline Yang $X Y, 2010$ & ? & $?$ & ? & $?$ & + & + & ? \\
\hline Zhang JL,2010 & + & $?$ & $?$ & ? & $?$ & + & ? \\
\hline Zhang MJ,2009 & ? & $?$ & $?$ & ? & $?$ & + & ? \\
\hline Zhang $S Q, 2014$ & ? & ? & ? & $?$ & $?$ & $\theta$ & ? \\
\hline Zhang XL,2005 & $?$ & $?$ & $?$ & $?$ & $?$ & + & $?$ \\
\hline 1ao JP, 2009 & $?$ & $?$ & $?$ & ? & $?$ & + & $?$ \\
\hline Zheng $Z P, 2012$ & + & + & $?$ & $?$ & $?$ & + & ? \\
\hline Zhou $Z Y, 2014$ & $?$ & $?$ & $?$ & $?$ & $?$ & + & ? \\
\hline Zou $H_{1} 2008$ & $?$ & $?$ & $?$ & $?$ & $?$ & $\oplus$ & ? \\
\hline Zou Y,2013 & $?$ & $?$ & $?$ & $?$ & + & + & ? \\
\hline
\end{tabular}

Figure 3: Risk of bias graph. Each risk of bias is presented as the percentage across all included studies. 


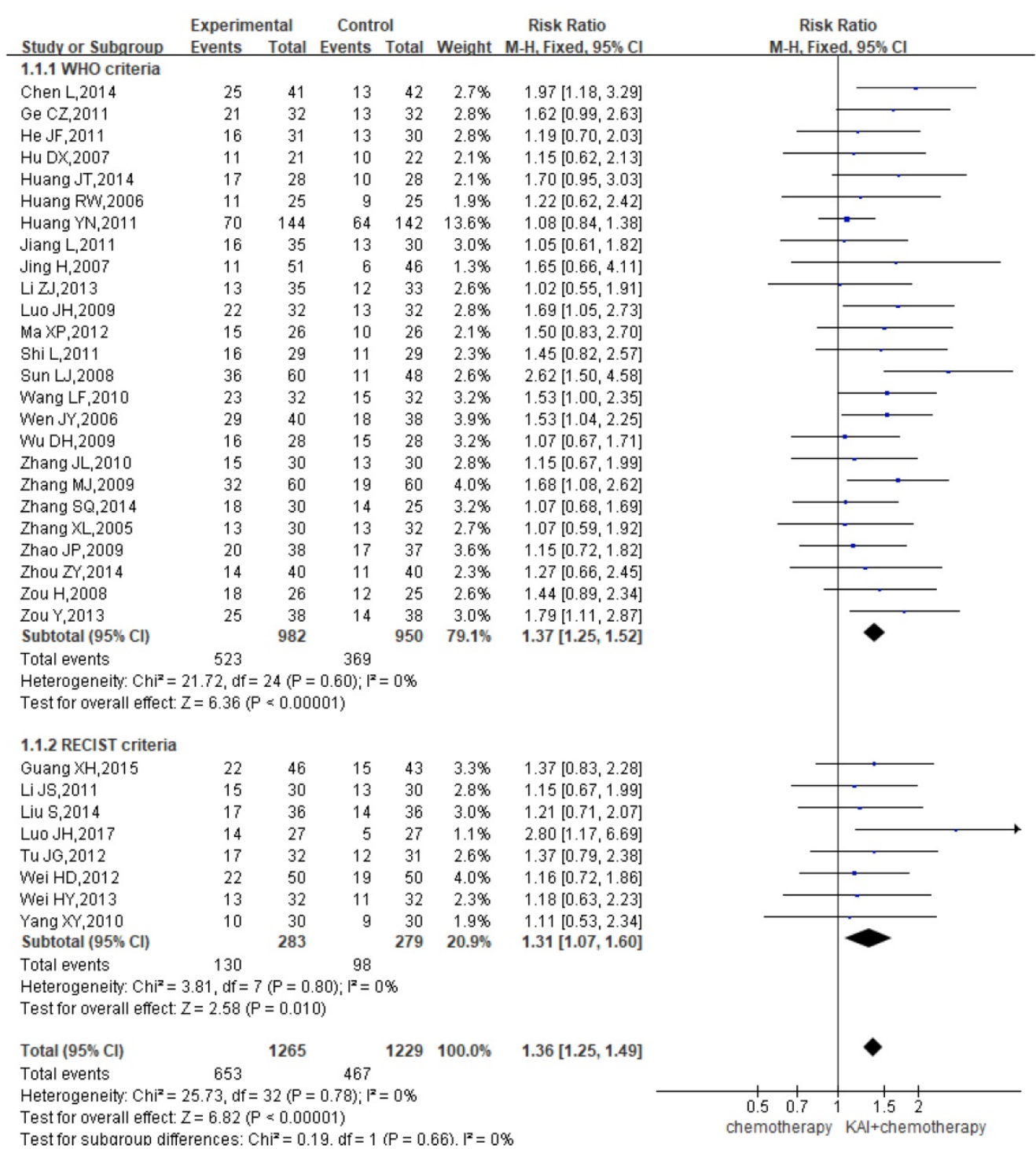

Figure 4: Forest plot showing objective response rates (ORR).

TSA indicated that the required information size (RIS) for a reliable and conclusive meta-analysis had been reached, and that KAI plus chemotherapy was significantly superior to the control intervention (Figure 11). These findings suggest that overall results for the analysis of ORR were robust. However, the quality of some included studies was low, which may have influenced estimates of sample size. including some studies is low, it will produce significant influence for the estimation of sample size.

MRA was also conducted to examine the effect of the number of KAI cycles on ORR and KPS. Our analysis revealed that KAI injection did not exert dose-dependent effects on ORR $[\log \mathrm{OR}=-0.009-0.014$ cycle number, $(\mathrm{u}=0.432, \mathrm{p}=0.666)]$ or $\mathrm{QOL}$ $[\log \mathrm{OR}=-0.006-0.019$ cycle number, $\quad(\mathrm{u}=0.987$, $\mathrm{p}=0.324)]$. Furthermore, both of these indices seemed to increase as the number of KAI cycles increased (Figures 12, 13).

\section{Discussion}

\section{Efficacy and safety analysis}

NSCLC is a common respiratory malignancy in China. Although platinum-based chemotherapy has improved the clinical efficiency of NSCLC treatment, the adverse reactions and immunosuppression associated with treatment significantly impact patient QOL, which may lead to discontinuation of treatment. Previous studies have demonstrated that KAI replenishes qi and enhances immune function when utilized as an adjuvant treatment for chemotherapy. Such findings have been observed among patients with primary liver cancer, colorectal cancer, and patients with NSCLC [66, 67]. Modern pharmacological studies have reported that ginseng can inhibit tumor cell growth and differentiation, increase the sensitivity of chemotherapy drugs, and 
enhance the immune function of peripheral blood lymphocytes in patients with cancer [68]. Astragalus has been reported to promote the induction of interferon or exert interferon-like effects, and to enhance anti-tumor effects by strengthening the activity of NK cells $[69,70]$. Additional research has indicated that matrine inhibits the proliferation and metastasis of tumor cells by inducing apoptosis, halting the cell cycle, and inhibiting the formation of blood vessels [71]. Hence, we conducted a meta-analysis to evaluate clinical efficiency, adverse reactions, and immune function in patients treated with platinum-based chemotherapy plus KAI for stage III/IV NSCLC.

Our systematic review included 35 studies involving a total of 2,618 patients. TSA of ORR suggested that the RIS for a conclusive and reliable meta-analysis had been reached, and that the combination of KAI and chemotherapy was significantly more effective than chemotherapy alone. ORR, DCR and QOL play an important role in assessing the clinical efficiency of NSCLC treatment. In this meta-analysis, we performed the subgroup analysis of ORR and DCR determined based on different criteria. This analysis revealed that KAI in combination with chemotherapy appeared to be more effective in improving ORR and DCR regardless of the criteria adopted. Our results further demonstrated that adjuvant treatment with KAI was associated with significant improvements in QOL as measured via KPS, suggesting that combined treatment enhances the tolerance to chemotherapy.

Although platinum-based chemotherapy can improve the efficiency of tumor treatment and QOL, the adverse reactions caused by chemotherapy may lead to poor rates of treatment adherence among patients. Indeed, chemotherapy frequently induces gastrointestinal reactions and myelosuppression. In

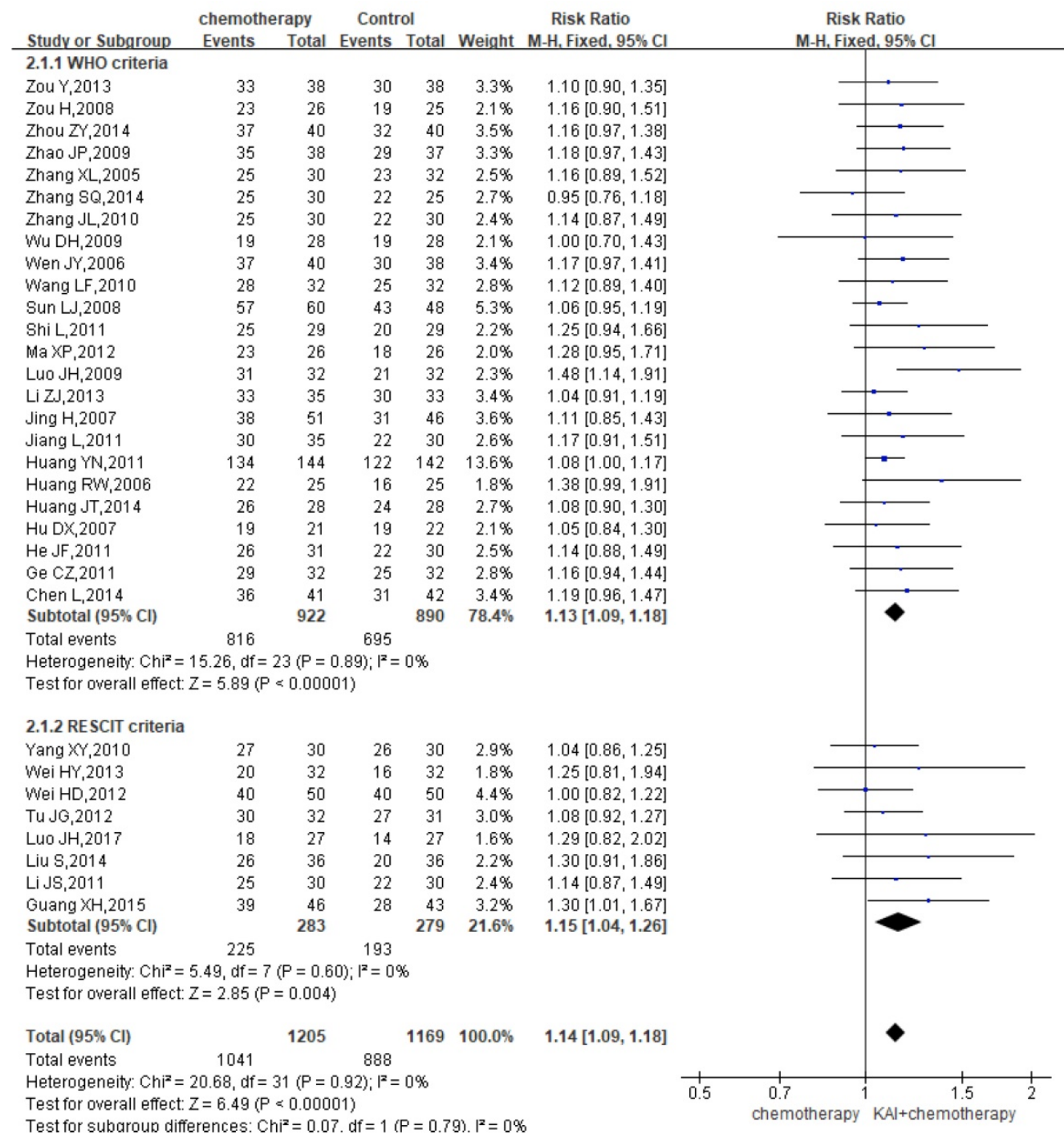

Figure 5: Forest plot showing disease control rates (DCR). 
order to evaluate the condition of myelosuppression rigorously, we performed meta-analysis of leukocyte, hemoglobin and platelet, respectively. Our meta-analysis revealed that adjuvant therapy with KAI may attenuate gastrointestinal reactions, reduce the incidence of leukocytopenia and thrombocytopenia of grade II or higher, while there was no significant difference in hemoglobin deficiency between the two groups.

The present meta-analysis marks the first attempt evaluate the effect of KAI on immune function during chemotherapy. Our results indicated that KAI combined with chemotherapy was significantly more effective in increasing the percentage of $\mathrm{NK}, \mathrm{CD}_{3}{ }^{+}$, and $\mathrm{CD}_{4}{ }^{+}$cells, and in decreasing the percentage of $\mathrm{CD}_{8}{ }^{+}$cells, when compared with chemotherapy alone. Furthermore, there was no significant difference in $\mathrm{CD}_{4}{ }^{+} / \mathrm{CD}_{8}{ }^{+}$ between the two groups. Taken together, these results suggest that KAI exert beneficial effects on chemotherapy-induced immune dysfunction. We then performed sensitivity analysis due to the high heterogeneity for $\mathrm{CD}_{4}{ }^{+}, \mathrm{CD}_{8}{ }^{+}$, and $\mathrm{CD}_{4}{ }^{+} / \mathrm{CD}_{8}{ }^{+}$indices. Although our results indicated good consistency among results, the observed heterogeneity may have influenced the stability and feasibility of our results.

Due to differences in tolerability and reactivity, KAI and chemotherapy regimens vary across patients. Therefore, we performed MRA of ORR and QOL, which revealed that KAI did not exert

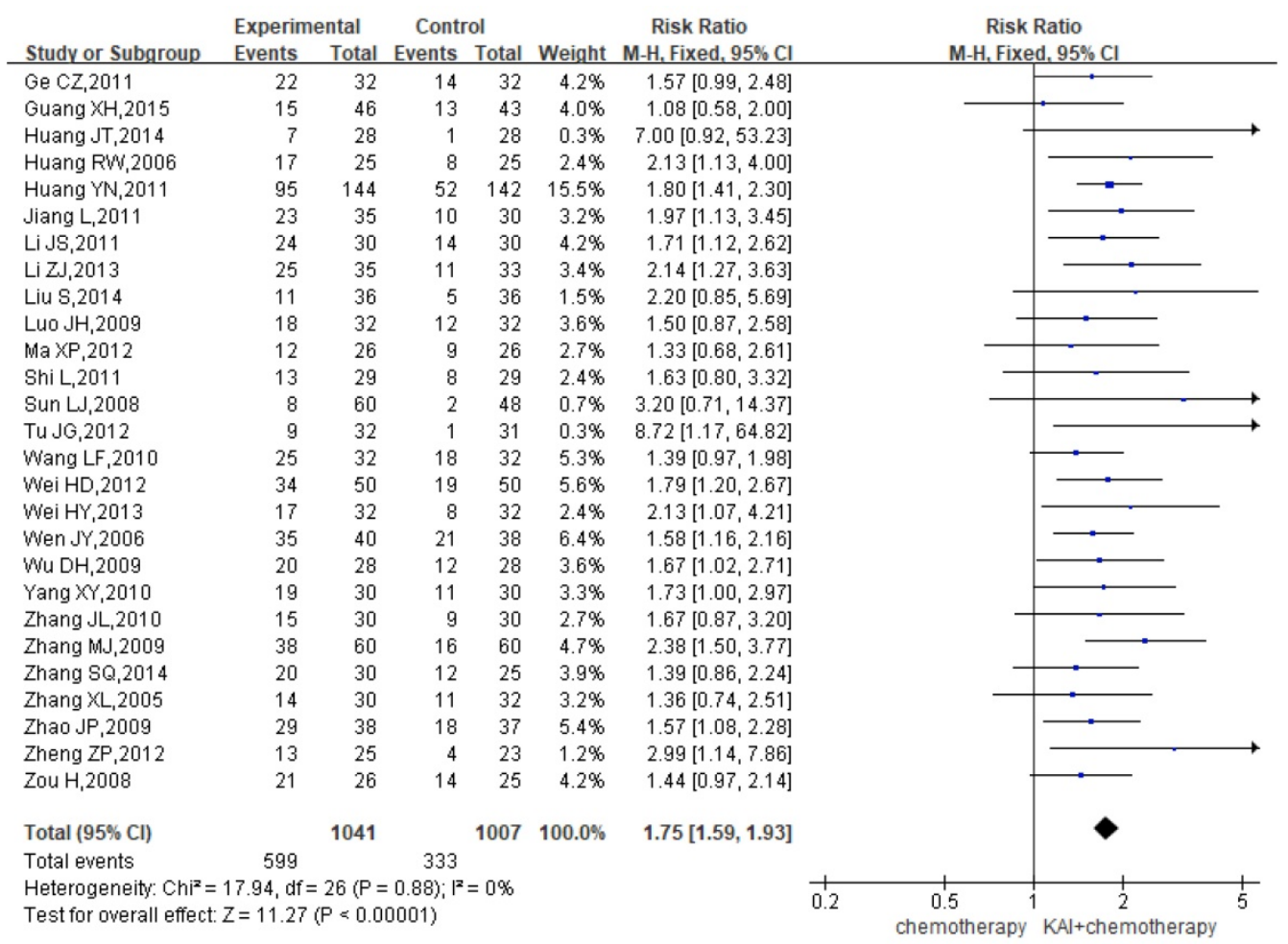

Figure 6: Forest plot showing quality of life (QOL) results for the included studies.

\begin{tabular}{|c|c|c|c|c|c|c|c|c|c|c|}
\hline \multirow[b]{2}{*}{ Study or Subgroup } & \multicolumn{2}{|c|}{ Experimental } & \multicolumn{2}{|c|}{ Control } & \multirow{2}{*}{\multicolumn{2}{|c|}{$\begin{array}{cc} & \text { Risk Ratio } \\
\text { Weight } & \text { M-H, Fixed, 95\% Cl } \\
\end{array}$}} & \multirow{2}{*}{\multicolumn{4}{|c|}{$\begin{array}{c}\text { Risk Ratio } \\
\text { M-H, Fixed, } 95 \% \mathrm{Cl}\end{array}$}} \\
\hline & Events & Total & Events & Total & & & & & & \\
\hline Huang JT,2014 & 2 & 28 & 5 & 28 & $2.6 \%$ & $0.40[0.08,1.89]$ & & & & \\
\hline Huang YN,2011 & 23 & 144 & 40 & 142 & $20.6 \%$ & $0.57[0.36,0.90]$ & & & & \\
\hline Jing $\mathrm{H}_{1} 2007$ & 11 & 51 & 11 & 46 & $5.9 \%$ & $0.90[0.43,1.88]$ & & & & \\
\hline Liu S,2014 & 5 & 36 & 11 & 36 & $5.6 \%$ & $0.45[0.18,1.18]$ & & & & \\
\hline Luo JH,2009 & 7 & 32 & 21 & 32 & $10.8 \%$ & $0.33[0.17,0.67]$ & & & & \\
\hline $\operatorname{MaXP}, 2012$ & 7 & 26 & 11 & 26 & $5.6 \%$ & $0.64[0.29,1.38]$ & & & . & \\
\hline Shi L,2011 & 7 & 29 & 11 & 29 & $5.6 \%$ & $0.64[0.29,1.41]$ & & & & \\
\hline Tu JG,2012 & 4 & 32 & 11 & 31 & $5.7 \%$ & $0.35[0.13,0.99]$ & & & & \\
\hline Wei HD,2012 & 21 & 50 & 25 & 50 & $12.8 \%$ & $0.84[0.55,1.29]$ & & & - & \\
\hline Wu DH,2009 & 11 & 28 & 19 & 28 & $9.7 \%$ & $0.58[0.34,0.98]$ & & & & \\
\hline Zhao JP,2009 & 2 & 38 & 4 & 37 & $2.1 \%$ & $0.49[0.09,2.50]$ & & & & \\
\hline Zou Y,2013 & 26 & 38 & 25 & 38 & $12.8 \%$ & $1.04[0.76,1.43]$ & & & . & \\
\hline Total $(95 \% \mathrm{Cl})$ & & 532 & & 523 & $100.0 \%$ & $0.64[0.54,0.77]$ & & & & \\
\hline Total events & 126 & & 194 & & & & & & & \\
\hline Heterogeneity: $\mathrm{Chi}^{2}=$ & $17.42, \mathrm{df}=$ & $11(P=$ & $=0.10) ;\left.\right|^{2}=$ & $=37 \%$ & & & 0.05 & 0.2 & 1 & 20 \\
\hline
\end{tabular}

Figure 7: Forest plot showing the incidence of gastrointestinal reactions for the included studies. 
dose-dependent effects on ORR and QOL. Moreover, both indices seemed to increase as the number of KAI cycles increased.

\section{Limitations of the included studies}

Although our results indicated that KAI combined with platinum-based chemotherapy is superior to chemotherapy alone with regard to improving clinical efficiency, reducing adverse reactions, and enhancing immune function, the included studies possess several limitations of note. First, although random allocation was utilized in all included studies, only nine of these studies reported the specific method of random allocation. While one study mentioned that opaque envelopes were used for allocation concealment, no such information was reported in the remaining studies, which may have resulted in selection bias. In addition, none of the 35 studies described the method of double-blinding or the blinding of outcome assessments. Only six articles reported rates of follow-up and withdrawal. Moreover, the results reported by four studies were less than the evaluation index in previous studies, suggestive of a certain degree of reporting bias. As the data were insufficient for the retrieved studies, sources of other bias remained unclear. In general, these potential sources of bias may have led to overestimation of curative efficiency, attenuating the strength of our conclusions. Second, it is possible that false-positive results were included, as the studies examined utilized an " $\mathrm{A}+\mathrm{B}$ " to " $\mathrm{B}$ " design without strict placebo controls. Third, because all included studies were published in Chinese, language bias may have influenced our results. Given these concerns, our results should be interpreted with caution and verified in more rigorous trials with high methodological quality.

\begin{tabular}{|c|c|c|c|c|c|}
\hline \multirow[b]{2}{*}{ Study or Subgroup } & \multicolumn{2}{|c|}{ Experimental } & \multicolumn{2}{|c|}{ Control } & \multirow[b]{2}{*}{ Weight } \\
\hline & Events & Total & Events & Total & \\
\hline Guang $\times \mathrm{H}_{1} 2015$ & 14 & 46 & 22 & 43 & $8.6 \%$ \\
\hline Huang JT,2014 & 3 & 28 & 10 & 28 & $3.8 \%$ \\
\hline Huang YN, 2011 & 37 & 144 & 62 & 142 & $23.6 \%$ \\
\hline Jing $\mathrm{H}, 2007$ & 19 & 51 & 23 & 46 & $9.1 \%$ \\
\hline Li ZJ 2013 & 4 & 35 & 9 & 33 & $3.5 \%$ \\
\hline Liu S,2014 & 6 & 36 & 18 & 36 & $6.8 \%$ \\
\hline Luo JH,2009 & 16 & 32 & 31 & 32 & $11.7 \%$ \\
\hline $\operatorname{Ma} X P, 2012$ & 3 & 26 & 7 & 26 & $2.6 \%$ \\
\hline Shi L,2011 & 3 & 29 & 7 & 29 & $2.6 \%$ \\
\hline Tu JG,2012 & 2 & 32 & 12 & 31 & $4.6 \%$ \\
\hline Wei HD,2012 & 6 & 50 & 10 & 50 & $3.8 \%$ \\
\hline Wei HY,2013 & 12 & 32 & 18 & 32 & $6.8 \%$ \\
\hline Wu DH,2009 & 10 & 28 & 18 & 28 & $6.8 \%$ \\
\hline Zhao JP, 2009 & 5 & 38 & 10 & 37 & $3.8^{\circ}-x-10$ \\
\hline Zou Y,2013 & 4 & 38 & 5 & 38 & $1.9 \%$ \\
\hline Total $(95 \% \mathrm{Cl})$ & & 645 & & 631 & $100.0^{\circ}$ \\
\hline Total events & 144 & & 262 & & \\
\hline
\end{tabular}
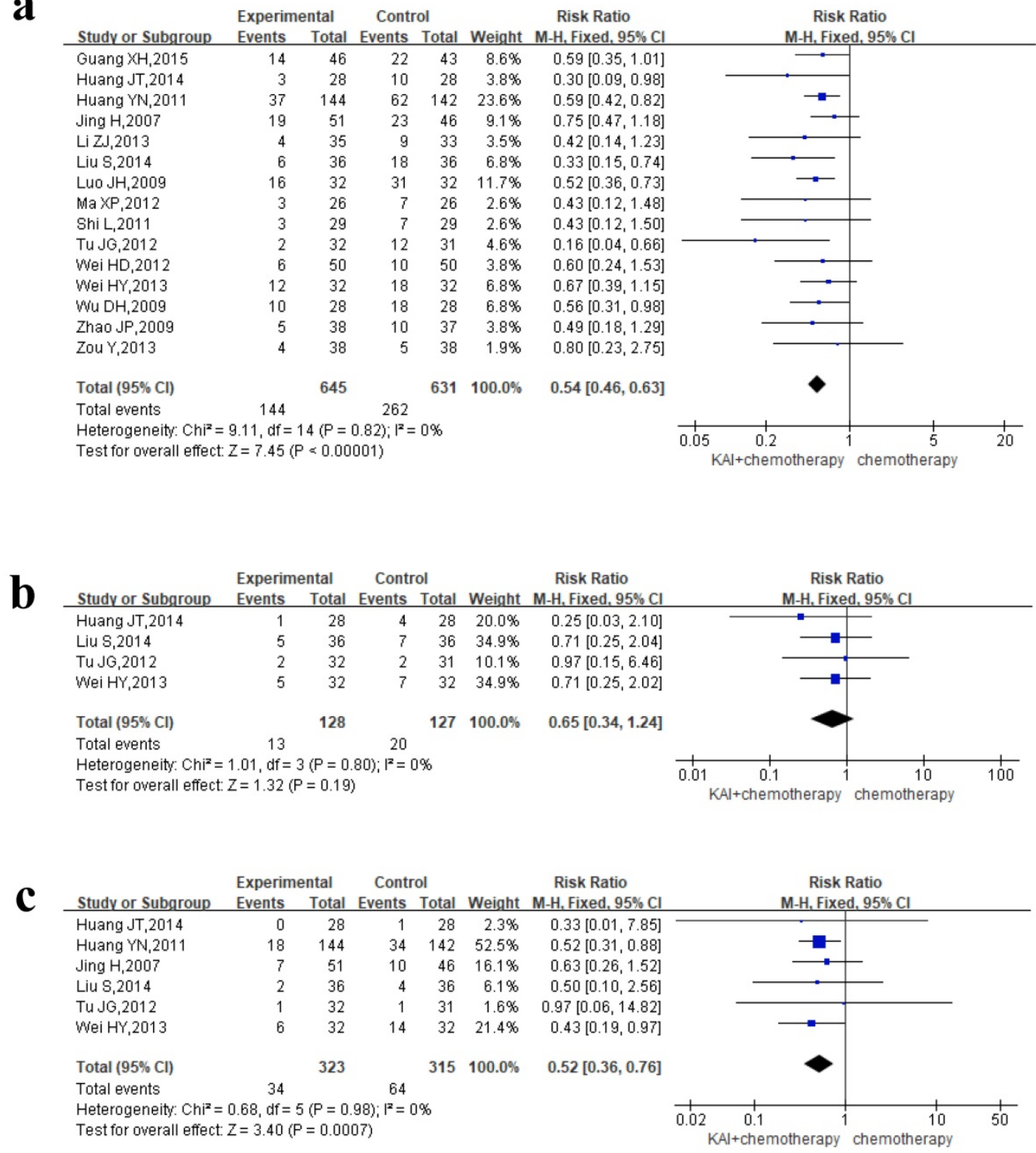

Figure 8: Forest plot showing rates of myelosuppression for the included studies: a. leukocytopenia; b. hemoglobin deficiency; c. thrombocytopenia. 


\section{Conclusions}

Our findings suggest that KAI combined with platinum-based chemotherapy is effective in improving ORR, DCR and QOL, attenuating chemotherapy-induced adverse effects, and regulating immune function in patients with NSCLC. complementary and alternative treatment for NSCLC. However, given the poor methodological quality of the included studies, our results should be interpreted with caution. Future RCTs with more rigorous designs should be conducted to yield more reliable conclusions to inform clinical practice.

Thus, KAI may be appropriate for use as a

$\mathbf{a}$

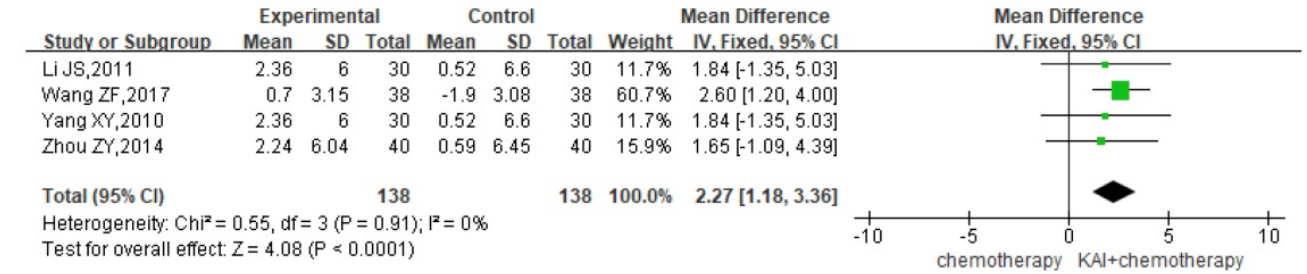

b

\begin{tabular}{|c|c|c|c|c|c|c|c|c|c|c|c|c|}
\hline \multirow[b]{2}{*}{ Study or Subgroup } & \multicolumn{3}{|c|}{ Experimental } & \multicolumn{2}{|c|}{ Control } & \multicolumn{3}{|r|}{ Mean Difference } & \multirow{2}{*}{\multicolumn{4}{|c|}{$\begin{array}{l}\text { Mean Difference } \\
\text { IV. Fixed, } 95 \% \mathrm{Cl}\end{array}$}} \\
\hline & Mean & SD & Total & Mean & SD & Total & Weight & IV. Fixed, 95\% Cl & & & & \\
\hline Chen L,2014 & 4.7 & 8.13 & 41 & -4.7 & 8.84 & 42 & $11.2 \%$ & $9.40[5.75,13.05]$ & & & $\longrightarrow$ & \\
\hline Wang ZF,2017 & 4.1 & 8.14 & 38 & -8.8 & 8.35 & 38 & $10.9 \%$ & $12.90[9.19,16.61]$ & & & $\rightarrow$ & \\
\hline Zhang $X L, 2005$ & -1.2 & 2.65 & 30 & -14.4 & 3 & 32 & $75.5 \%$ & $13.20[11.79,14.61]$ & & & $\square$ & \\
\hline Zheng ZP,2012 & 6.32 & 14.55 & 25 & -11.96 & 13.55 & 23 & $2.4 \%$ & $18.28[10.33,26.23]$ & & & & \\
\hline Total $(95 \% \mathrm{Cl})$ & & & 134 & & & 135 & $100.0 \%$ & $12.86[11.64,14.08]$ & & & $\bullet$ & \\
\hline $\begin{array}{l}\text { Heterogeneity: } \mathrm{Chi}^{2}= \\
\text { Test for overall effect. }\end{array}$ & $\begin{array}{l}5.46, d f \\
Z=20.6\end{array}$ & $\begin{array}{l}=3(\mathrm{P}= \\
11(\mathrm{P} \approx 0\end{array}$ & $\begin{array}{l}0.14) ; \\
00001\end{array}$ & $\left.\right|^{2}=45 \%$ & & & & & -20 & -10 & 10 & 20 \\
\hline
\end{tabular}

c

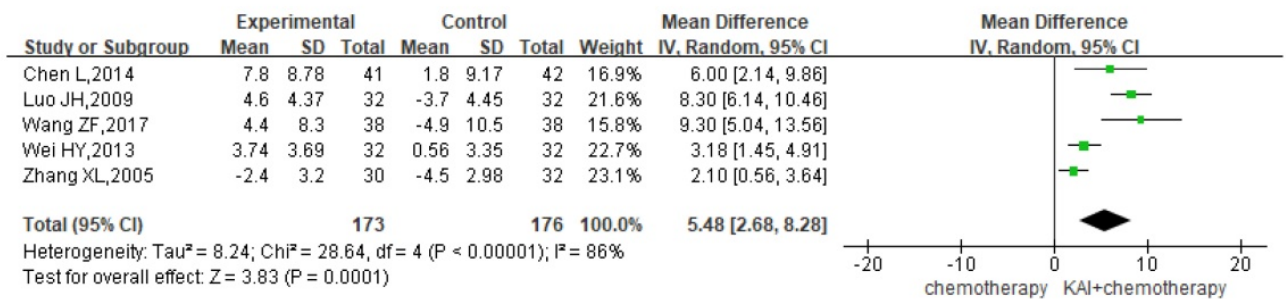

d

\begin{tabular}{|c|c|c|c|c|c|c|c|c|c|c|c|}
\hline \multirow[b]{2}{*}{ Study or Subgroup } & \multicolumn{3}{|c|}{ Experimental } & \multicolumn{2}{|c|}{ Control } & \multirow{2}{*}{\multicolumn{2}{|c|}{ Total Weight }} & \multirow{2}{*}{$\begin{array}{l}\text { Mean Difference } \\
\text { IV, Random, } 95 \% \mathrm{Cl}\end{array}$} & \multirow{2}{*}{\multicolumn{3}{|c|}{$\begin{array}{c}\text { Mean Difference } \\
\text { IV, Random, } 95 \% \mathrm{Cl}\end{array}$}} \\
\hline & Mean & SD & Total & Mean & SD & & & & & & \\
\hline Chen L,2014 & -2.2 & 8.07 & 41 & 4.6 & 9.36 & 42 & $14.7 \%$ & $-6.80[-10.56,-3.04]$ & & & \\
\hline Luo JH,2009 & -0.8 & 3.04 & 32 & -0.6 & 3.02 & 32 & $23.8 \%$ & $-0.20[-1.68,1.28]$ & & & \\
\hline Wang ZF, 2017 & -0.3 & 7.1 & 38 & 5.5 & 8.66 & 38 & $15.4 \%$ & $-5.80[-9.36,-2.24]$ & & & \\
\hline Wei HY,2013 & -0.5 & 4.13 & 32 & -0.95 & 3.8 & 32 & $21.9 \%$ & $0.45[-1.49,2.39]$ & & & \\
\hline Zhang $X L, 2005$ & 1.3 & 2.39 & 30 & 3.5 & 2.98 & 32 & $24.3 \%$ & $-2.20[-3.54,-0.86]$ & -- & & \\
\hline Total $(95 \% \mathrm{Cl})$ & & & 173 & & & 176 & $100.0 \%$ & $-2.37[-4.51,-0.23]$ & & & \\
\hline $\begin{array}{l}\text { Heterogeneity: Tau }{ }^{2} \\
\text { Test for overall effect }\end{array}$ & $\begin{array}{l}4.43 ; \mathrm{Cl} \\
\mathrm{Z}=2.18\end{array}$ & $\begin{array}{l}i^{2}=21 \\
\langle P=0\end{array}$ & $\begin{array}{l}1.10, d f \\
.03)\end{array}$ & $=4(\mathrm{P}=$ & $=0.000$ & 03); $1^{2}=$ & $81 \%$ & & -20 & 10 & 20 \\
\hline
\end{tabular}

e

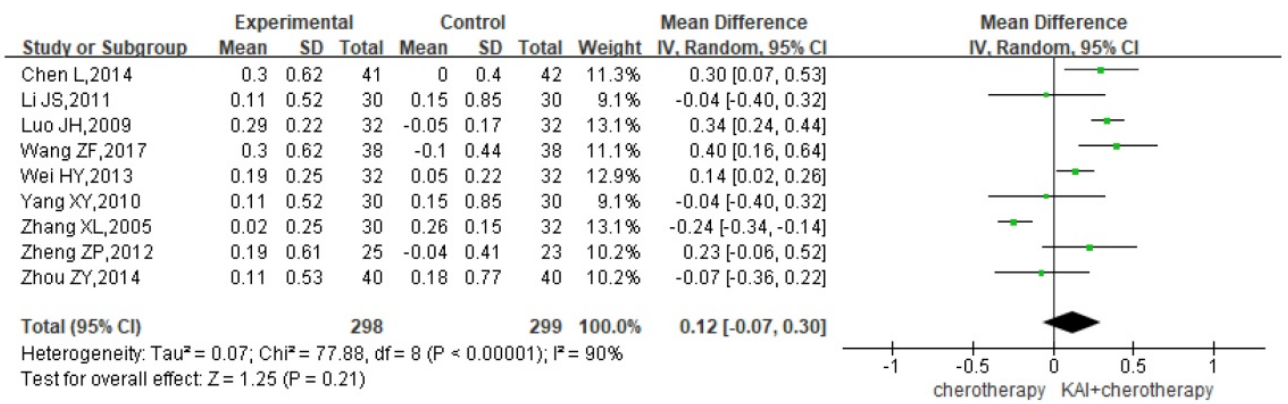

Figure 9: Forest plot shows immune index. a. NK; b. CD3+; c. CD4+; d. CD8+; e. CD4+/CD8+. 


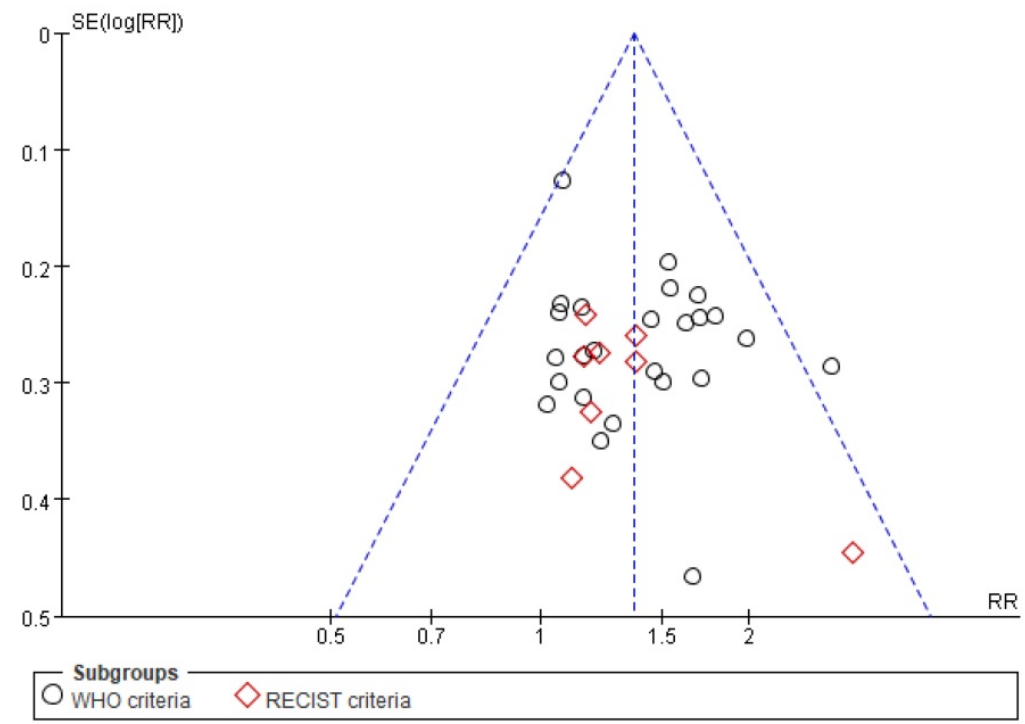

Figure 10: Funnel plot of ORR.

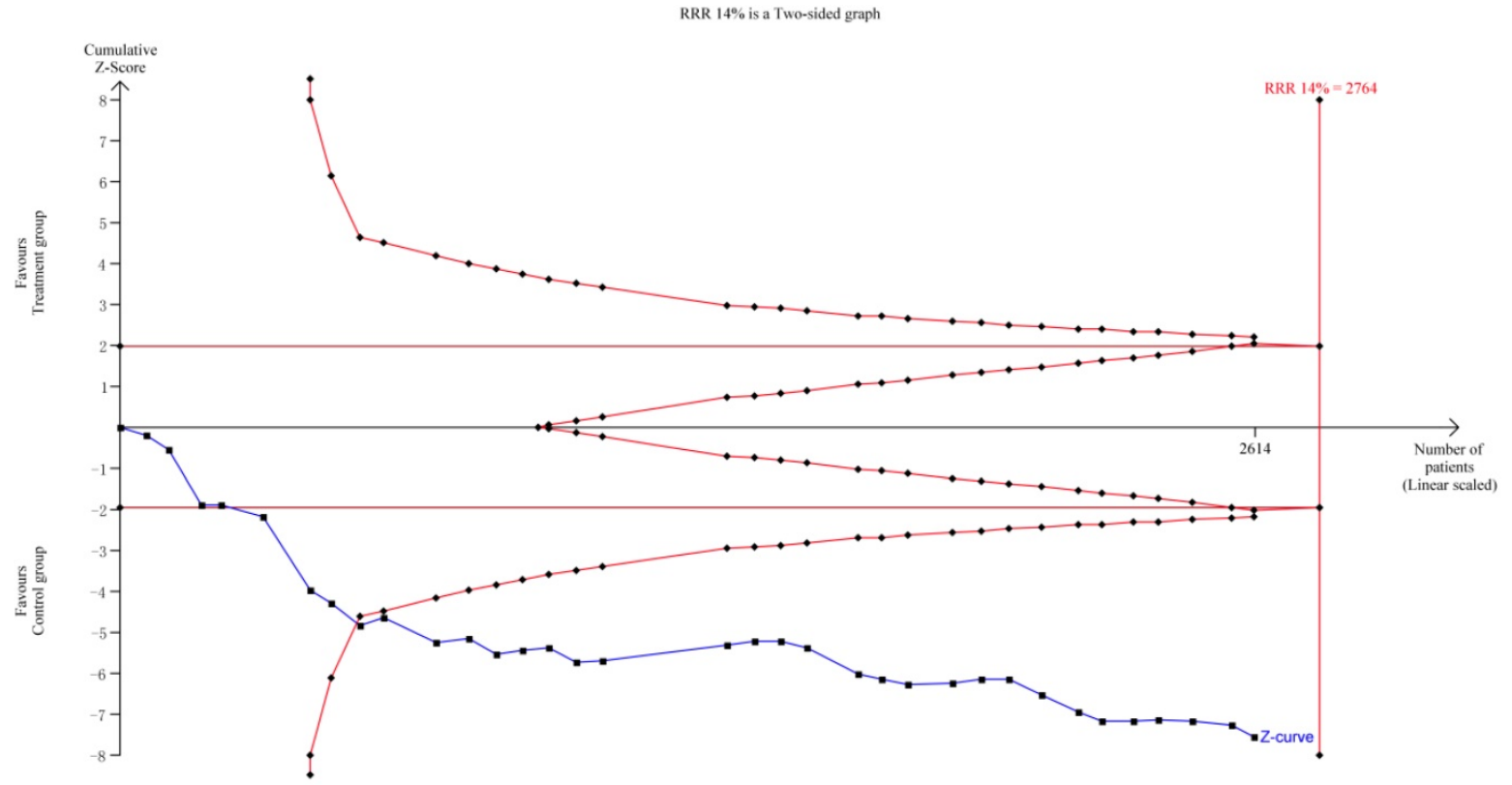

Figure 11: Trial sequential analysis on ORR.

Regression of Cycle number on Log risk ratio

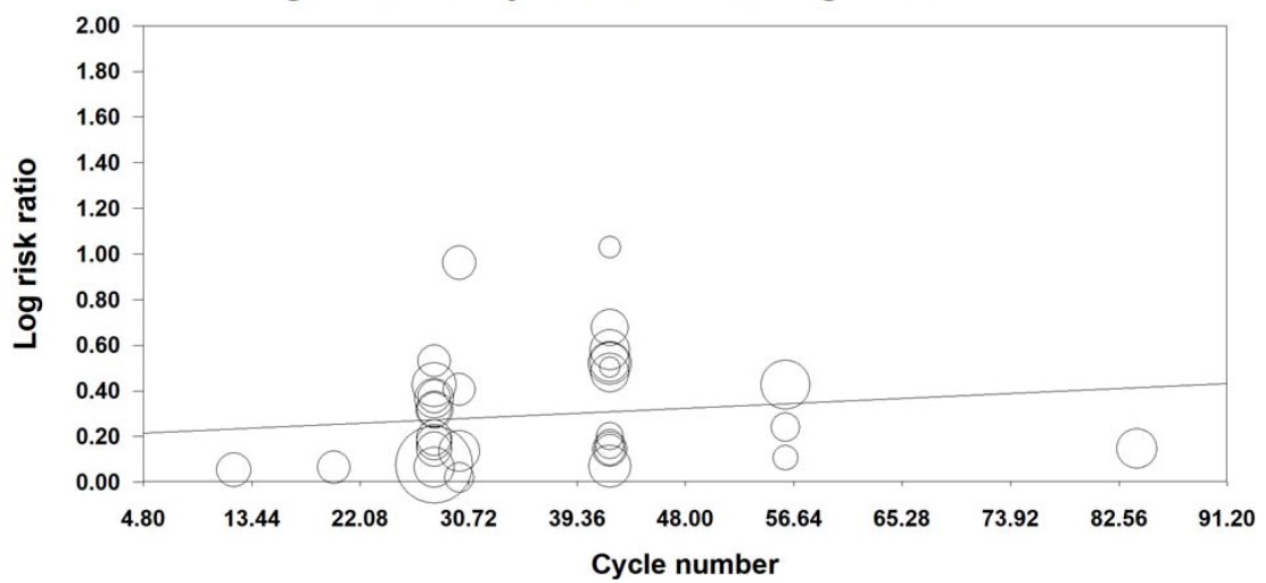




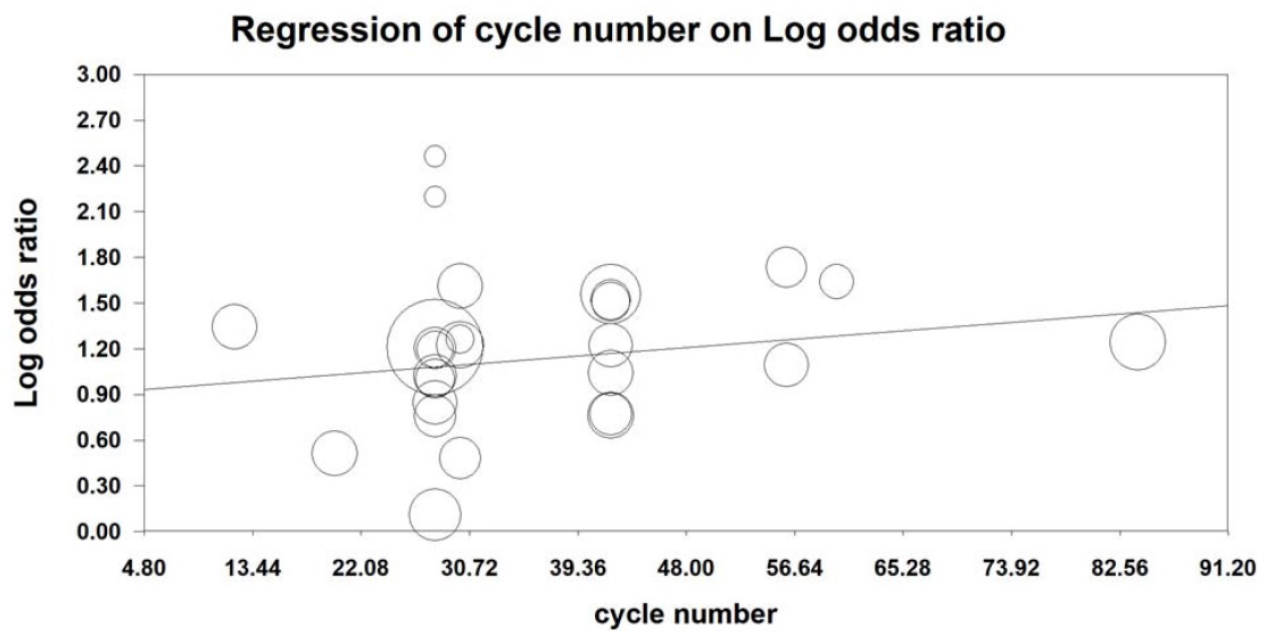

Figure 13: Meta-regression analysis on QOL.

\section{Abbreviations}

KAI: kangai injections; NSCLC: non-small cell lung cancer; RCT: randomized controlled trials; CMA: comprehensive meta-analysis; ORR: objective response rate; QOL: quality of life; TCM: traditional Chinese medicine; CPM: Chinese patent medicine; CNKI: Chinese National Knowledge Infrastructure; CBM: Chinese Biological Medicine; VIP: VIP Database for Chinese Technical Periodicals; PRISMA: Preferred Reported Items for Systematic Review and Meta-analysis; PROSPERO: International Prospective Register of Systematic Reviews; KPS: Karnofsky performance scores; WHO: World Health Organization; RECIST: Response Evaluation Criteria in Solid Tumors; CR: complete relief; PR: partial remission; $\mathrm{SD}$ : stable disease; $\mathrm{PD}$ : progressive disease; CMA: Comprehensive Meta-Analysis; RR: Risk ratio; MD: mean differences; CI: confidence intervals; TSA: Trial sequential analysis; MRA: meta-regression analysis; NK: natural killer cells.

\section{Supplementary Material}

Supplementary table and search strategy.

http://www.jcancer.org/v10p5283s1.pdf

\section{Acknowledgments}

This work was supported by the People Programme (Marie Curie Actions) of the European Union's Seventh Framework Programme FP7/2007-2013/ under REA grant agreement No. PIRSES-GA-2013-612589: CHETCH (China and Europe Taking Care of Healthcare Solutions), the Key Project of Jiangsu Provincial Education Department (16KJA360001), and the National Natural Science Foundation of China (81503374).

\section{Author Contributions}

Hongxiao Li: design, collecting data, statistical analysis, writing the article, final approval of the article.

Yuejin Ji: design, collecting data, statistical analysis, editing the final text, final approval of the article.

Shiping Zhang: collecting data, statistical analysis, final approval of the article.

Zishan Gao: collecting data, critical revision, final approval of the article.

Cheng Hu: collecting data, critical revision, final approval of the article.

Rilei Jiang: collecting data, critical revision, final approval of the article.

Meijuan Chen: collecting data, critical revision of the article, final approval of the article.

Guochun Li: conception, design, statistical analysis, critical revision of the article, final approval of the article.

$\mathrm{Xu}$ Zhang: conception, design, supervising the whole process, critical revision of the article, final approval of the article.

\section{Competing Interests}

The authors have declared that no competing interest exists.

\section{References}

1. Siegel RL, Miller KD, Jemal A. Cancer statistics, 2018. CA Cancer J Clin. 2018;68:7-30

2. Torre LA, Sauer AMG, Chen MS, Kagawa-Singer M, Jemal A, Siegel RL. Cancer statistics for Asian Americans, Native Hawaiians, and Pacific Islanders, 2016: Converging incidence in males and females. CA: A Cancer Journal for Clinicians. 2016;66:182-202.

3. Yip C, Blower PJ, Goh V, Landau DB, Cook GJR. Molecular imaging of hypoxia in non-small-cell lung cancer. Eur J Nucl Med Mol I. 2015;42:956-76.

4. Johnson ML, Patel JD. Chemotherapy and Targeted Therapeutics as Maintenance of Response in Advanced Non-Small Cell Lung Cancer. Semin Oncol. 2014;41:93-100. 
5. Hsia T, Tu C, Fang H, Liang J, Li C, Chien C. Cost and effectiveness of image-guided radiotherapy for non-operated localized lung cancer: a population-based propensity score-matched analysis. J Thorac Dis. 2015;7:1643-9.

6. Anagnostou VK, Brahmer JR. Cancer Immunotherapy: A Future Paradigm Shift in the Treatment of Non-Small Cell Lung Cancer. Clin Cancer Res. 2015;21:976-84.

7. Yajuan Z, De C, Jianpeng Z. Research Advances in Resistance to Platinum-based Chemotherapy in Lung Cancer. Acta Academiae Medicinae Sinicae. 2017;39:150-5.

8. Zhong LLD, Chen H, Cho WCS, Meng X, Tong Y. The efficacy of Chinese herbal medicine as an adjunctive therapy for colorectal cancer: A systematic review and meta-analysis. Complement Ther Med. 2012;20:240-52.

9. $\mathrm{Cao} \mathrm{A}, \mathrm{He} \mathrm{H}$, Jing $\mathrm{M}, \mathrm{Yu}$ B, Zhou X. Shenfu Injection Adjunct with Platinum-Based Chemotherapy for the Treatment of Advanced Non-Small-Cell Lung Cancer: A Meta-Analysis and Systematic Review. Evid-Based Compl Alt. 2017;2017:1-12.

10. Suxian Z, Xiansong Z. Methodological Quality Assessment of Systematic Reviews and Meta-analysis in Fields of Integrated Chinese-western Terapy for Non-small Cell Lung Cancer. Chinese Journal of Evidence-Based Medicine. 2016;16:1231-5.

11. Congcong W, Hongxing L, Jin Z, Ruijuan L, Xiaohua C, Changgang S. Efficacy and Safety of Traditional Chinese Medicine Combined With Concurrent Chemoradiotherapy in Treatment of Advanced Non-small Cell Lung Cancer: A Meta-analysis. Chinese General Practice. 2015;18:1406-14.

12. Wenxia S, Min C, Mingjian C, et al. Progress on clinical application of Kang-ai injection. Modern Hospitals. 2014;14:47-49.

13. Sun M, Ye Y, Xiao L, et al. Anticancer effects of ginsenoside Rg3 (Review). Int J Mol Med. 2017;39:507-518.

14. Chen T, Li B, Qiu Y, et al. Functional mechanism of Ginsenosides on tumor growth and metastasis. Saudi J Biol Sci. 2018;25:917-922.

15. Jung YY, Shanmugam MK, Narula AS, et al. Oxymatrine Attenuates Tumor Growth and Deactivates STAT5 Signaling in a Lung Cancer Xenograft Model. Cancers (Basel). 2019;11:49. doi: 10.3390/cancers11010049.

16. Dai $Z$, Wang $L$, Wang $X$, et al. Oxymatrine induces cell cycle arrest and apoptosis and suppresses the invasion of human glioblastoma cells through the EGFR/PI3K/Akt/mTOR signaling pathway and STAT3. Oncol Rep. 2018;40:867-876.

17. Liu Y, Qin L, Bi T, et al. Oxymatrine Synergistically Potentiates the Antitumor Effects of Cisplatin in Human Gastric Cancer Cells. J Cancer. 2018:9:4527-4535

18. Zou M, Wang J, Gao J, et al. Phosphoproteomic analysis of the antitumor effects of ginsenoside $\mathrm{Rg} 3$ in human breast cancer cells. Oncol Lett, 2018;15:2889-2898.

19. Mohanan P, Subramaniyam S, Mathiyalagan R, et al. Molecular signaling of ginsenosides Rb1, Rg1, and Rg3 and their mode of actions. J Ginseng Res. 2018;42:123-132.

20. Liu QY, Yao YM, Zhang SW, et al. Astragalus polysaccharides regulate T cell-mediated immunity via CD11c(high)CD45RB(low) DCs in vitro. J Ethnopharmacol. 2011;136:457-64.

21. Zhou X, Liu Z, Long T, et al. Immunomodulatory effects of herbal formula of astragalus polysaccharide (APS) and polysaccharopeptide (PSP) in mice with lung cancer. Int J Biol Macromol. 2018;106:596-601.

22. Ma J, Liu H, Wang X. Effect of ginseng polysaccharides and dendritic cells on the balance of Th1/Th2 T helper cells in patients with non-small cell lung cancer. J Tradit Chin Med. 2014;34: 641-645.

23. Huiting F, Hongsheng L. Review on Clinical Application and Basic Research of Kang'ai Injection on Cancer. Cancer Research on Prevention and Treatment. 2014;41:1045-1048.

24. Zhou X, Liu Z, Long T, et al. Immunomodulatory effects of herbal formula of astragalus polysaccharide (APS) and polysaccharopeptide (PSP) in mice with lung cancer. Int J Biol Macromol. 2018;106:596-601.

25. Xie $\mathrm{Q}$, Wen $\mathrm{H}$, Zhang $\mathrm{Q}$, et al. Inhibiting PI3K-AKt signaling pathway is involved in antitumor effects of ginsenoside Rg3 in lung cancer cell. Biomed Pharmacother. 2017:85:16-21.

26. Jiahua L, Zenghui L, Zhongming T. Clinical Curative Effect of Kangai Injection Combined with Chemotherapy for Non-Small Cell Lung Cancer. Jilin Medical Journal. 2017;38:830-1.

27. Xinhui G. Comprehensive evaluation of Kangai injection combined with chemotherapy in the treatment of advanced NSCLC. Journal of North Pharmacy. 2015;12:26-7.

28. Yue Z. The clinical effect of Kangai injection combined with NP regimen in the treatment of advanced non-small cell lung cancer. Zhejiang Clinical Medical Journal. 2013;15:639-41.

29. Zujin L, Mengxi C. Kangai Injection Combined with NP Chemotherapy for 35 Patients with Advanced Non-small Cell Lung Cancer. Chinese Medicine Modern Distance Education of China. 2013;11:54-5.

30. Wang X, Hongsheng L, Liyuan L, et al. A meta-analysis of Kang ai injection combined with chemotherapy in the treatment of advanced non-small cell lung cancer. J Cancer Res Ther. 2015;11:558-64.

31. He XR, Han SY, Li PP. Injectable Chinese herbal formula Kang'ai for non small cell lung cancer: Trial sequential analysis of 2,259 participants from 31 randomized controlled trials. J Cancer Res Ther. 2016;12:735-43.
32. Higgins JPT GS. Cochrane Handbook for Systematic Reviews of Interventions Version 5.1.0 [updated March 2011]: The Cochrane Collaboration; 2011

33. Zhifeng W. Effect of First-line Platinum-based Chemotherapy Combined with Kangai Injection on Advanced Non-small Cell Lung Cancer. Clin Med. 2017;37:101-2.

34. Lun C. Effect of Kangai injection on immune function and quality of life in patients with advanced non-small cell lung cancer during chemotherapy. Guiding Journal of Traditional Chinese Medicine and Pharmacy. 2014;20:29-31.

35. Zongyuan Z. Clinical observation of Kangai injection combined with cisplatin chemotherapy in non small cell lung cancer. chinese community doctors. 2014;30:82-3.

36. Shuo L, Hui W, Hongsheng L. Clinical Observation of Combined Kangai Injection with Chemotherapy in The Treatment of Advanced Non-small Cell Lung Cancer. world chinese medicine. 2014;9:323-5.

37. Junting $\mathrm{H}$. The effect of Kangai injection combined with TP regimen in the treatment of elderly patients with advanced non-small cell lung cancer. Contemporary Medicine. 2014;20:145-6.

38. Shengqi Z, Lifang L, Hongbin Z, Xihui Q, Xiaowen Z, Zhiming C. Clinical efficacy of Kangai injection combined with chemotherapy in treatment of advanced lung cancer: An observation of 55 cases. China Medicine and Pharmacy. 2014;4:62-4.

39. Yue Z. The clinical effect of Kangai injection combined with NP regimen in the treatment of advanced non-small cell lung cancer. Zhejiang Clinical Medical Journal. 2013;15:639-41.

40. Zujin L, Mengxi C. Kangai Injection Combined with NP Chemotherapy for 35 Patients with Advanced Non-small Cell Lung Cancer. Chinese Medicine Modern Distance Education of China. 2013;11:54-5.

41. Ma X, Hui Y, Hu A. Clinical Efficacy Analysis of Kangai Injection in Patients with Advanced Non-small Cell Lung Cancer. Journal of Chengdu College. 2012;7:300.

42. Zhaopeng Z, Shiyun X, Weibing Y, Qing S, Libin H, Hongfei L, et al. Clinical study of kang'ai Injection combined with chemotherapy in the treatment of advanced lung cancer. Journal of Zunyi Medical University. 2012:35:209-12.

43. Jianguo T. Clinical Study on Kangai Injection Combined with Chemotherapy for Elderly Patients with Advanced Non-small Cell Lung Cancer. Chinese Journal of Clinical Rational Drug Use. 2012;5:56-7.

44. Haidong W, Xiaoping W, Yixin W, Hong W, Hongyan T, Huirong H, et al. Kangai injection and NP therapy in the treatment for 50 cases of non-small cell lung cancer. Western Journal of Traditional Chinese Medicine. 2012;25:57-9.

45. Changzheng G, Yanhua X, Dingfu Z, Xingzi H. Clinical Observation on 32 Cases of Elderly Advanced Non-small Cell Lung Cancer Treated by Kangai Injection Combined with Chemotherapy. Guiding Journal of Traditional Chinese Medicine and Pharmacy. 2011;17:24-6.

46. Lin J, Qingzhi K, Xianzhu H. Kangai injection combined with DP chemotherapy regimen for the treatment of advanced non-small cell lung cancer. Journal of Hubei University of Chinese Medicine. 2011;13:62-3.

47. Jinsong L, Liang H, Baolan Y, Xiumei D. Clinical observation of combined Kangai injection with chemotherapy in the treatment of advanced non-small cell lung cancer. Journal of China Traditional Chinese Medicine Information. 2011;3:53-5.

48. Lei S. Clinical Effect Observation of Kangai Injection in Treating Advanced Non-small Cell Lung Cancer with TP Chemotherapy. China Practical Medicine. 2011;6:151-2.

49. Liufei W, Yong W. Clinical observation of TP chemotherapy combined with Kangai injection in the treatment of non-small cell lung cancer. Chinese Community Doctors. 2010:12:64-5.

50. Xiaoyu Y, Suqin L, Jie Z, Ling W, Tao Z. Kangai injection combined with GC regimen for elderly patients with advanced non-small cell lung cancer. journal of new chinese medicine. 2010;42:73-5.

51. Jinlin Z, Lei Y. Clinical observation of combined Kangai injection with TP in the treatment of advanced non-small cell lung cancer. Modern Oncology. 2010;18:1132-4

52. Jianhua L, Ruixiang L, Qin L, Lin H. Kangai injection combined with NP regimen in the treatment of 32 patients with advanced non-small cell lung cancer. Cancer Research and Clinic. 2009;21:483-5.

53. Danhong W, Naijie C, Yunying C, Yiqin L. Kangai injection combined with paclitaxel plus DDP chemotherapy for advanced non-small cell lung cancer in 28 cases. Fujian Journal of Traditional Chinese Medicine. 2009;40:20-1.

54. Mingjuan Z, Caifeng Z, Linqiang C. Clinical Observation of Kangai Injection Combined with Chemotherapy in the Treatment of Middle and Late Non-small Cell Lung Cancer. Shanghai Medical \& Pharmaceutical Journal. 2009;30:213-5.

55. Jingping Z. Clinical analysis of Kangai injection combined with docetaxel and cisplatin in the treatment of advanced non-small cell lung cancer. China Modern Doctor. 2009;47:25-6.

56. Han Z, Hong W. Clinical Observation on 26 Cases of Advanced Non-small Cell Lung Cancer Treated by Kangai Injection Combined with TP Chemotherapy. Journal of New Chinese Medicine. 2008;40:26-7.

57. Hua J, Mingfeng L. Short-term therapeutic effect of integrated Kangai injection and chemotherapy on patients with non-small cell lung cancer. Chinese Journal of Clinical Pharmacy. 2007;16:303-5. 
58. Dingxue H, Rongyan C, Yanwei L, Zhizheng Y, Qun M. Clinical efficacy of combined chemotherapy with Kangai injection plus NP regimen in treatment of advanced non-small cell lung cancer. Chinese Journal of Clinical Oncology and Rehabilitation. 2007;14:427-9.

59. Ruiwen H, Huaqiang L, Yong L, Sixian C. Clinical observation of Kang' ai injection combined with NP regimen in the treatment of advanced non- small cell lung cancer. China Journal of Modern Medicine. 2006;8:22-4.

60. Jiyu W, Zhong $X$, Jierong $X$, Liping $F$. Kangai injection mixed with chemotherapy in intermediate and advanced-stage non-small cell lung cancer. Journal of Guangdong Medical College. 2006;24:13-4.

61. Xinglin Z, Xia L. Kangai injection combined with chemotherapy in the treatment of advanced non-small cell lung cancer. Chinese Journal of Integrated Traditional and Western Medicine. 2005;25:543-4.

62. Yunna H. Kangai injection's enhancement in patients with advanced non-small cell lung cancer. Journal of China Traditional Chinese Medicine Information. 2011;3:20-2.

63. Jianfei H. Clinical observation of Kangai injection combined with TP regimen in the treatment of middle and late stage lung cancer. The 12th National Lung Cancer Academic Conference of China Lung Cancer Professional Committee of Cancer Society; 2011; p. 429-30.

64. Hongyan W. Clinical observation of Kangai injection combined with DP chemotherapy in advanced non-small cell lung cancer [master's degree]. Hebei Medical University. 2013.

65. Lijuan S. Clinical observation on treating non-small cell lung cancer with Kangai injection and chemotherapy. Chinese Health Care. 2008;16:1-2.

66. Huiting F, Hongsheng L. Review on Clinical Application and Basic Research of Kang'ai Injection on Cancer. Cancer Research on Prevention and Treatment. 2014;41:1045-8.

67. Yifan Y, Xiaoyeu C, Baoxia L, Xiao L, Ruihong L, Jinlong Q, et al. Simultaneous determination of 11 components in Kang'ai Injection by UPLC-MS/MS. Chinese Traditional and Herbal Drugs. 2017;48:2660-5.

68. Linming L, Yaning S, Yina J, Jihua Z, Li Q, Naihong C. Advance in components with antitumor effect of Panax ginseng and their mechanisms. Chinese Traditional and Herbal Drugs. 2017;48:582-96.

69. Lingli W, Hualing F, Ke Y, Hongmei T, Zhenghai H. Research Progress on Biology and Chemical Constituents of Astragalus membranaceus. Genomics and Applied Biology. 2017;36:2581-5.

70. Qin L, Jihong $\mathrm{H}$, Bo G, Haidong L, Shuang S, Lixia Y. Advances on Immunoregulation Effect of Astragalus Polysaccharides. Chinese Journal of Experimental Traditional Medical Formula. 2017;23:199-206.

71. Linfeng G, Shanshan T, Jiangnan Y, Ximing X. Research Progress on anti-tumor mechanism of Matrine. China Journal of Chinese Materia Medica. 2013;38:3409-12. 